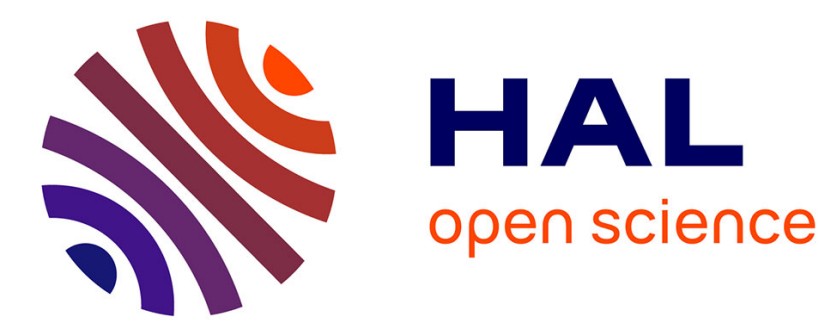

\title{
Criteria for the preparation of cross-linked poly(meth)acrylate microparticles by solution free radical polymerization
}

Sébastien Rouzeau, Françoise Méchin, Jean-Pierre Pascault, Benoît Magny

\section{- To cite this version:}

Sébastien Rouzeau, Françoise Méchin, Jean-Pierre Pascault, Benoît Magny. Criteria for the preparation of cross-linked poly(meth)acrylate microparticles by solution free radical polymerization. European Polymer Journal, 2007, 43 (10), pp.4398-4414. 10.1016/j.eurpolymj.2007.07.015 . hal-02080388

\section{HAL Id: hal-02080388 \\ https://hal.science/hal-02080388}

Submitted on 26 Mar 2019

HAL is a multi-disciplinary open access archive for the deposit and dissemination of scientific research documents, whether they are published or not. The documents may come from teaching and research institutions in France or abroad, or from public or private research centers.
L'archive ouverte pluridisciplinaire HAL, est destinée au dépôt et à la diffusion de documents scientifiques de niveau recherche, publiés ou non, émanant des établissements d'enseignement et de recherche français ou étrangers, des laboratoires publics ou privés. 


\title{
Criteria for the preparation of cross-linked poly(meth)acrylate microparticles by solution free radical polymerization
}

\author{
Sébastien ROUZEAU ${ }^{\mathrm{a}) c}$, Françoise MECHIN $^{\mathrm{a}}{ }^{*}$, Jean-Pierre PASCAULT ${ }^{\mathrm{a} \text {, }}$ \\ Benoît MAGNY ${ }^{\mathrm{b}) \mathrm{d})}$
}

a) Laboratoire des Matériaux Macromoléculaires, Ingénierie des Matériaux Polymères (LMM/IMP) UMR CNRS \#5223

INSA-Lyon, Bâtiment Jules Verne,

20, avenue Albert Einstein, F-69621 VILLEURBANNE Cedex, France

b) Cray Valley - Total Chimie, Centre de Recherche de l'Oise, BP22

60550 VERNEUIL EN HALATTE, France

Published in European Polymer Journal vol. 43, 4398-4414 (2007)

c) present address : Viscotek France, ZI de la Mouche, 69540 IRIGNY, France

d) present address :12, place de l'Iris, La Défense 2, 92062 PARIS LA DEFENSE, France

corresponding author: Françoise MECHIN

fmechin@insa-lyon.fr $\quad$ tel. :33.4.72.43.85.48 fax: 33.4.72.43.85.27 


\title{
Criteria for the preparation of cross-linked poly(meth)acrylate microparticles by solution free radical polymerization
}

\author{
Sébastien ROUZEAU ${ }^{\mathrm{a}) c}$, Françoise MECHIN ${ }^{\mathrm{a})}$ *, Jean-Pierre PASCAULT ${ }^{\mathrm{a})}$, \\ Benoît MAGNY ${ }^{\mathrm{b}) \mathrm{d})}$ \\ a) Laboratoire des Matériaux Macromoléculaires, Ingénierie des Matériaux Polymères \\ (LMM/IMP) UMR CNRS \#5223 ; INSA-Lyon, Bâtiment Jules Verne, \\ 20, avenue Albert Einstein, F-69621 VILLEURBANNE Cedex, France \\ b) Cray Valley - Total Chimie, Centre de Recherche de l'Oise, BP22 \\ 60550 VERNEUIL EN HALATTE, France
}

\begin{abstract}
Cross-linked Polymer Microparticles (CPMs) with nanoscopic size were synthesized from the free radical polymerization of acrylate/diacrylate mixtures or of their methacrylate counterparts. The syntheses were carried out in solution, and the study of the influence of the solvent on the CPM characteristics led to the definition of reliable criteria for the obtention of true, soluble, individualized microgels and for avoiding macrogelation, when starting from any desired monomer combination. Two main parameters could be pointed out: first, the probability of propagation of the growing radicals, $q$, (or the kinetic chain length $\lambda=1 / 1-q$ ) that must be kept below a certain threshold value in order to prevent macrogelation; $q$ may be adjusted by playing on the monomer, initiator and transfer agent concentrations. The second essential criterion is the ability of the copolymer for auto-stabilization in the chosen solvent (that may be adjusted by the use of a suitable stabilizing co-monomer in case the quality of the solvent would not be sufficient), in order to avoid flocculation and interparticular reactions. By controlling these two parameters, the preparation of CPMs becomes possible over a wide range of concentration and composition.
\end{abstract}

Keywords: cross-linked polymer microparticle; microgel; solution free radical polymerization; auto-stabilization; kinetic chain length 


\section{Introduction}

Cross-linked Polymer Microparticles, CPMs, are defined as intramolecularly crosslinked macromolecules [1]. Also commonly known as microgels (or sometimes nanogels) for many years, they can be viewed as a new, fourth class of polymers (besides linear, branched macromolecules and macroscopic polymer networks), on the border between molecules and particles [1-3]. Due to their nanoscopic size and compact structure, CPMs now find applications in numerous practical and/or industrial fields, for instance as components for binders in organic coatings, nanometric carriers for numerous dyes, pharmaceutical or biochemical compounds used in immuno assays and controlled drug delivery systems [4], or high performance fillers in plastics, thermosetting polymers or coatings [5,6].

These special macromolecular objects are based on at least one monomer with a functionality greater than 2 , as a crosslinking agent. But polymerizing such systems can obviously and very easily lead to macrogelation. Therefore the numerous methods now available for the synthesis of micro- and nanogels mainly rely on two distinct general concepts in order to avoid macrogelation: either the use of reactors with micro/nanoscopic sizes (i.e. the droplets of an emulsion, of a miniemulsion or of a dispersion), or the very high dilution of the reacting medium.

The first examples used the emulsion (oil/water) free radical polymerization of styrene/divinylbenzene [1,7], unsaturated polyesters/comonomers $[1,8,9]$ or methacrylic systems, with or without surfactant [3,10]. More recent works were devoted to the free radical polymerization of the same or of other systems in miniemulsion [11,12], logically leading to much smaller particles. Numerous studies were also focused on the preparation of polymer particles by dispersion polymerization, but most of them were non-cross-linked and of micron-size [13-16]. A few years ago, even polyadditions in micro-sized dispersions were developed for the synthesis of polyurethane micro/nanospheres, for example by reacting 
dispersed diols with tolylene diisocyanate dissolved in a non-polar continuous phase (typically cyclohexane or supercritical $\mathrm{CO}_{2}$ ) in the presence of a functional stabilizer, but usually the resulting particles were not cross-linked either [17-20].

Other techniques are simply based on the use of ultra dilute conditions in solution: internal cyclization is then favored $v s$. intermolecular crosslinking. Historically, the very first example of CPM synthesis was indeed the preparation of microgels by the free radical polymerization of divinylbenzene under highly dilute conditions by Staudinger [21]. Later on, these experimental conditions were used either directly for the polymerization reaction $[1,22,23]$ or for post-self-crosslinking reactions of functional macromolecules [24,25]. Finally an elegant way of "virtually" diluting the system without adding more solvent is to use controlled radical polymerization, since in this case the instant radical concentration is much lower than under conventional free radical polymerization conditions. Both nitroxidemediated polymerization [26] and atom transfer radical polymerization [27] were used for that purpose.

In solution, transfer agents can also be added in order to delay macrogelation [28,29]. More generally, Stöver et al. proposed a two-stage mechanism for CPM formation by solution polymerization [30]. The first stage would be the formation of highly swollen oligomers; and the second stage would be microgel growth through intermolecular reactions between oligomers, or between oligomers and growing microgels. Besides these reactions, cyclization should also be extensive whereas internal crosslinking should be limited by maximized solvent swelling. This would result in a limited diameter for the growing microgels, since cyclization would reduce the number of available double bonds at the microgel's surface. This mechanism reveals the importance of the quality of the solvent for the growing polymer chains; the same parameter was also highlighted by Graham who showed that for a given and well-defined range of solubility parameters for the chosen solvent, it was possible to avoid 
macrogelation and to obtain CPMs even at rather to quite high concentrations [2,22,31,32]. The same even holds when step growth polymerization is used instead of free radical polymerization, especially for the synthesis of polyurethane microgels [31]. According to Graham, primary, intramolecularly cross-linked particles would be formed at first and would gradually aggregate through covalent bonds. In a very good solvent, the chains formed at first would point out of the microparticles and act as auto-stabilizers by creating repulsive forces between the particles, thus allowing to avoid macrogelation even at high concentration.

The "microgels" described in the literature can have real nanometric sizes, but can also be rather micrometric particles, somewhat different from the definition given by Funke et al. [1]. In contrast, this paper is especially devoted to CPMs or microgels with very small diameters (below $50 \mathrm{~nm}$ ). It describes the synthesis and characterization of new CPMs and of their homologous linear polymers, mainly prepared by the free radical copolymerization of lauryl acrylate (LA), butyl acrylate (BA) and cardura acrylate (CA), with hexanediol diacrylate (HDDA) as a crosslinking agent. The aim was to use solution polymerization, with as little solvent as possible. It was thus necessary to understand precisely the role of the solvent in these reactions. For comparison purposes, the use of analogous reacting systems based on methacrylates was also addressed.

\section{Experimental Part}

\section{Materials}

Several acrylate monomers and their methacrylate counterparts were used for crosslinked microparticle synthesis. Their structures and suppliers are shown in Table 1, together with their solubility parameter calculated according to Fedor's group contribution method [33]. The free radical polymerizations were carried out in solution using three different solvents: heptane (SDS, 95\% n-heptane $+5 \%$ branched isomers), isopropanol, iPrOH (SDS, 
99.7\%) and methylethylketone (SDS, 99.0\%). The initiator was 2,2'-azobis(2methylbutyronitrile), AMBN (Vazo 67, DuPont) whereas 1-dodecanethiol (RSH, Aldrich, 98\%) was sometimes used as a transfer agent. All these materials were used without purification.

Monomers based on glycidyl neodecanoate (Cardura E10)

Cardura acrylate and methacrylate are two monomers often used for automotive coatings [34,35]. In our case, they were synthesized by Cray Valley using acrylic or methacrylic acid and glycidyl neodecanoate (or Cardura E10, Hexion Specialty Chemicals) [36], with tin bis(ethylhexanoate), $\mathrm{Sn}(\mathrm{Oct})_{2}$, as a catalyst. Cardura E10 is the product of the reaction between epichlorohydrin and versatic (tert-decanoic) acid and is a mixture of isomers. A quick ${ }^{1} \mathrm{H}$ NMR analysis of this precursor revealed that only $85 \%$ of the versatic chains were actually linked to an epoxide group (I). In the literature [37], this compound was shown to also often contain the corresponding diol (II) and diester (III), as represented in Figure 1.

The synthesis of CA is depicted in Figure 2. Two main products should be obtained, bearing one hydroxyl group either in primary (IV) or secondary position (V). Although the reaction between an epoxide and a carboxylic acid was sometimes found to lead to high amounts of secondary alcohol [38], in this particular case the ${ }^{1} \mathrm{H}$ NMR spectrum revealed a majority of the primary $\mathrm{OH}$ derivative, IV. The molar proportion between these two isomers (IV/V) is about $80 / 20$. This is generally observed when the synthesis is carried out at low temperature without catalyst or with $\mathrm{Sn}(\mathrm{Oct})_{2}$, whereas higher temperatures and other catalysts usually lead to major amounts of the secondary alcohol that could indeed be the thermodynamically stable product [34].

However, this mixture was obtained from a precursor with only $85 \mathrm{~mol} \%$ of the epoxide derivative. Therefore the non-reactive impurities initially contained in Cardura E10 
should still be present (since esterification between the alcoholic impurities, II and III, and (meth)acrylic acid is unlikely to occur under the used experimental conditions). Nevertheless, a chemical titration of the hydroxyl groups of CA (reaction with excess acetic anhydride, then back titration with potassium hydroxide) led to a global value $\left(\mathrm{I}_{\mathrm{OH}}=185[ \pm 1.5 \%] \mathrm{mg}_{\mathrm{KOH}} / \mathrm{g}\right)$ very close to that expected $\left(\mathrm{I}_{\mathrm{OH}}=187 \mathrm{mg}_{\mathrm{KOH}} / \mathrm{g}\right.$ ) for the pure product (IV or V). The presence of the diol, II, almost exactly compensates for the lack of $\mathrm{OH}$ groups brought by the diester, III. Therefore, the overall molar composition of the "cardura acrylate", CA, used in this study should be:

* $70 \mathrm{~mol} \%$ CA with a primary $\mathrm{OH}$ group (IV)

* 15 mol\% CA with a secondary $\mathrm{OH}$ group (V)

* $15 \mathrm{~mol} \%$ diol + diester (II and III)

The SEC analysis of CA indeed showed a second peak with a lower retention time, that could correspond to the diester, III. The peak associated with the diol, II, cannot be detected since it presumably has about the same retention volume as CA (IV or V).

II and III should not be reactive in the free radical polymerization, except if some transfer to the $\mathrm{CA}$ monomer or to its different impurities with rather similar chemical structures could exist (since isopropanol was also found to cause some transfer, see below). To check that, a model saturated molecule was synthesized from the reaction between Cardura E10 and propanoic acid, using exactly the same experimental conditions as for CA synthesis. Butyl acrylate was then polymerized in heptane solution $\left(70^{\circ} \mathrm{C}\right)$, either alone or in the presence of the resulting Cardura propanoate, $\mathrm{CP}$, added in amounts comparable with those used for CA in the copolymers and CPMs described below. Without $\mathrm{CP}$, the obtained average molar masses were $M_{n}=47.9 \mathrm{~kg} / \mathrm{mol}$ and $M_{w}=137 \mathrm{~kg} / \mathrm{mol}$, whereas in the presence of $\mathrm{CP}_{\mathrm{n}}=49.2 \mathrm{~kg} / \mathrm{mol}$ and $\mathrm{M}_{\mathrm{w}}=132 \mathrm{~kg} / \mathrm{mol}$ were found. Therefore any transfer to Carduraderived molecules seems rather negligible. 


\section{Cross-linked microparticle synthesis}

Model linear copolymers were synthesized by a batch process, using an initial mixture of $75 \mathrm{wt} \%$ solvent and $25 \mathrm{wt} \%$ monomers; the temperature of the mixture was set to $70^{\circ} \mathrm{C}$ and the initiator, dissolved in the same solvent, was then added.

In contrast, a semi-continuous process was defined and used for the preparation of cross-linked polymer microparticles, CPMs. In a first stage, $30 \%$ of the monomers, plus almost all the solvent, were put in the reaction vessel and heated up to $70^{\circ} \mathrm{C}$. After that, the remaining monomers, together with the initiator solution, were added dropwise over 90 and 40 min, respectively.

In every case, the overall monomer amount lied between 0.4 and $0.5 \mathrm{~mol}$, and the corresponding overall monomer concentration, between 1.0 and $1.5 \mathrm{~mol} / \mathrm{L}$. The initiator concentration was set to $10 \mathrm{mmol} / \mathrm{L}$ and the reaction was stopped after 6 hours, a time sufficient to reach a conversion beyond $95 \%$ for acrylate double bonds [39 and see below]. For methacrylates, the same criterion required longer reaction times (about $34 \mathrm{~h}$ at $70^{\circ} \mathrm{C}$ ).

In order to simplify the calculations for monomer mixtures, termination was always considered to occur only through disproportionation, although this can in fact depend on the nature of the monomer and on the temperature.

\section{Characterization}

Chemical structures were analyzed by ${ }^{1} \mathrm{H}$ NMR in $\mathrm{CDCl}_{3}$, using a Bruker DRX 400 spectrometer operating at $400 \mathrm{MHz}$.

Molar masses of the linear polymers and of the CPMs were determined by Size Exclusion Chromatography using the principle of universal calibration (SEC-UC), as described in another paper [40]. This method allows the determination of molar masses of any type of copolymer, which cannot be achieved with conventional SEC, together with that of the Mark-Houwink-Sakurada exponent, $a$ (the intrinsic viscosity, $[\eta]=\mathrm{M}^{a}$ ). Our previous 
work [40] indeed showed that in a typical CPM synthesis, all the macromolecules have the same degree of crosslinking for their structure, whatever their size. The experimental conditions used for the synthesis lead only to a definite type of CPM molecules with a homogeneous density, and not to a mixture of linear, branched copolymers and cross-linked macromolecules, even though the molar mass distribution can be broad. In the same article [40], it was also shown that SEC-MALLS obviously overestimates radii of gyration of these small-sized particles, and that SEC-UC is thus more convenient to obtain accurate values. Here the SEC-UC method was processed in THF $(1 \mathrm{~mL} / \mathrm{min})$ with three Styragel HR 5E columns (mixed bed: extended range of porosity) from Waters in series, heated at $35^{\circ} \mathrm{C}$. The chromatograph was equipped with a VE 3580 refractometer (RI) and T60A intrinsic viscosity detector from Viscotek. Polymer solutions were prepared with concentrations ranging from 1 to $4 \mathrm{mg} / \mathrm{mL}$ in THF. $100 \mu \mathrm{L}$ of solution was injected onto the columns for each measurement. The refractometer and viscometer were calibrated using different PS standards of known concentrations and viscosities.

\section{Results and discussion}

In his paper, Valette [39] described the synthesis of several CPMs by free radical polymerization in various organic media. Macrogelation was avoided by the use of a reactive surfactant comonomer, or "surfmer", that displayed a very low solubility parameter and provided the microparticles with an auto-dispersing character. Several mixtures of heptane and isopropanol were used as solvent, and especially good results (microgels with z-average radius of gyration, $R_{z}$, as low as $20 \mathrm{~nm}$ ) were obtained with a 50/50 weight ratio (solubility parameter, $\delta=20.3 \mathrm{MPa}^{1 / 2}$ ). This ratio, as well as the polymer overall composition and concentration, seemed to have a huge influence on the possibility to avoid macrogelation and on the microparticle characteristics. Therefore the question remains whether the formation of 
true microgels is best achieved by dispersion (as stated by Valette) or solution free radical polymerization, and what is the exact role of the solvents used for the reaction. In this work, we tried to determine some reliable criteria in order to achieve microgelation, if possible using a single solvent and as high as possible monomer concentrations.

\section{Effect of the solvent}

Two different aspects should be considered when selecting a solvent for the synthesis of CPMs with a well-defined composition. Of course, its solubility parameter, $\delta$, should have a great influence [2]. But one should also take into account the possible ability of this solvent to act as a transfer agent, when considering a free radical polymerization with a rather high amount of solvent.

A monomer mixture with a simple composition, CA/BA/HDDA (20/75/5 mol\%) was selected to study and compare the influence of these two parameters. An average solubility parameter can be calculated for CPMs with this composition using a group contribution method [33] leading to $\delta=18.6 \mathrm{MPa}^{1 / 2}$. Therefore both methylethylketone $\left(\delta=19.0 \mathrm{MPa}^{1 / 2}\right)$ and heptane/iPrOH $\left(50 / 50 \mathrm{wt} \%, \delta=20.5 \mathrm{MPa}^{1 / 2}\right)$ should be good solvents for this copolymer. Dissolution experiments with a model linear copolymer, based on CA/BA (20/80 mol\%), indeed revealed that it was entirely soluble in both of them, but also in pure isopropanol (and despite its higher $\delta=23.5 \mathrm{MPa}^{1 / 2}$, denoting the limits of such an approach). In contrast, heptane $\left(\delta=15.1 \mathrm{MPa}^{1 / 2}\right)$ turned out to be a poor solvent for this copolymer, although pure poly(butylacrylate) is entirely soluble in heptane. This different behavior can be attributed to the presence of cardura acrylate units, that bear $\mathrm{OH}$ groups able to establish hydrogen bonds with the solvent in the case of isopropanol, whereas it is not possible with heptane.

The above mixture was then polymerized in each of the four solvents, and the results are displayed in Table 2. A macroscopic, solvent-swollen gel was obtained in methylethylketone (a good solvent), whereas the copolymer coagulated in heptane (a poor 
solvent). In contrast, soluble CPMs $(a<0.5$ in SEC-UC) were formed in pure isopropanol as well as in the mixture with heptane. Therefore solubility itself cannot account for the result obtained (micro- vs. macro-gelation). However, the molar mass obtained for CPMs in pure isopropanol is lower than that of the CPMs synthesized in heptane/iPrOH, suggesting that iPrOH might also act as a transfer agent in the free radical polymerization. Indeed when the CPMs are prepared in heptane/iPrOH mixtures with increasing proportions of heptane, increasing molar masses and polydispersities are obtained, until a threshold composition beyond which macrogelation always occurs. At this point, both $\mathrm{M}_{\mathrm{w}}$ and $\mathrm{I}_{\mathrm{p}}$ diverge. These results are depicted in Figure 3 and confirm iPrOH transfer.

In order to have a more quantitative approach of this transfer, another experiment consisted in polymerizing butyl acrylate in heptane, adding small but increasing amounts of iPrOH, with the aim of determining the chain transfer constant for that simple system. After an analysis by SEC-UC, it was possible to determine the cumulative polymerization degree, $\left(D P_{n}\right)_{c u m}$ (which should correspond to a conversion equal to $95 \%$, see above), then to plot $1 /\left(D P_{n}\right)_{\text {cum }}$ versus the initial transfer agent $[\mathrm{iPrOH}]$ concentration. This curve is represented in Figure 4, and can be described by eq. 1 (the equations used to obtain equation 1 are displayed in Appendix A):

$$
\frac{1}{\left(D P_{n}\right)_{\text {cum }}}=K+\frac{1-(1-\alpha)^{C_{\text {irroH }}}}{\alpha[M]_{0}}[i \operatorname{PrOH}]
$$

where $\alpha$ stands for the conversion and $\mathrm{C}_{\mathrm{iPrOH}}$ for the chain transfer constant.

From the slope of the curve depicted in Figure $4(\alpha=95 \%), k$, it is possible to calculate $\mathrm{C}_{\mathrm{iPrOH}}$ using the following equation:

$$
C_{\text {iPrOH }}=\frac{\ln \left(1-\alpha[M]_{0} k\right)}{\ln (1-\alpha)}
$$

Using $[M]_{0} \approx 1.42 \mathrm{~mol} / \mathrm{L}$, the value found for $\mathrm{BA}$ at $70^{\circ} \mathrm{C}$ is $\mathrm{C}_{\mathrm{iPrOH}}=18.5 \cdot 10^{-4}$. Of course this value is only an approximation, since the conversion, $\alpha=0.95$, was only 
estimated, and since other transfer reactions might also occur. But it is consistent with other data from the literature, i.e. $\mathrm{C}_{\mathrm{iPrOH}}=14 \cdot 1 \cdot 10^{-4}$ for butyl acrylate at $80^{\circ} \mathrm{C}$ [41].

\section{Effect of a transfer agent}

In order to dissociate solubility and solvent transfer effects, the synthesis was run once again in pure heptane (poor solvent), adding controlled amounts of an efficient transfer agent ; 1-dodecanethiol, RSH, was selected for that purpose. First of all, the chain transfer constant was calculated for RSH in the same way as above for the polymerization of BA in heptane at $70^{\circ} \mathrm{C}$. The results are represented in Figure 5; from these data, it comes out that $\mathrm{C}_{\mathrm{RSH}}=0.39$. RSH should thus produce the same transfer effect as $\mathrm{iPrOH}$, when used in amounts $\sim 200$ times lower. Attempts to synthesize CPMs (based on CA/BA/HDDA 20/75/5 mol\%) in pure heptane or methylethylketone were then made by adding low, controlled amounts of RSH; these amounts were selected in order to induce a transfer equivalent to that provided by $\mathrm{iPrOH}$ in the mixtures used by Valette [39]. More precisely, and according to the chain transfer constant ratio determined just above, heptane/iPrOH (50/50 wt $\%)$ should correspond to an initial $\mathrm{RSH}$ concentration of about $0.025 \mathrm{~mol} / \mathrm{L}$ in pure heptane.

These results are presented in Table 3. In this case, macrogelation was never observed, even in heptane. In methylethylketone $+\mathrm{RSH}$ or heptane/iPrOH $(50 / 50 \mathrm{wt} \%)$, both good solvents, almost similar results were obtained. This tends to confirm our calculated rate constants and the fact that $[\mathrm{RSH}]=0.025 \mathrm{~mol} / \mathrm{L}$ is roughly equivalent to $50 \mathrm{wt} \%$ of $\mathrm{iPrOH}$. However, the same amount of RSH in heptane, a poor solvent, was not sufficient to obtain a clear solution of CPMs. The polydispersity index and the gyration radius were also much higher in this solvent. Although the transfer agent lowers the length of the growing polymer chains and the probability of early intermolecular reactions, these particular CPMs remain insoluble in heptane and tend to flocculate; this finally enables some intermolecular crosslinks, hence the very high polydispersity and the final cloudy aspect of the mixture. 
A first criterion for microgelation can thus be deduced from these experiments: in a good solvent like methylethylketone, the probability of intermolecular reactions should be minimized, and under such conditions the addition of a transfer agent that limits the length of the growing polymer chains, especially at the moment when they become cross-linked, should allow to avoid macrogelation. In this respect, it should be particularly useful to lower the parameter $q=\frac{r_{p}}{r_{p}+r_{t}+\Sigma r_{t r}}$ (depending on the propagation, termination by disproportionation and various transfer rates $r_{p}, r_{t}$ and $r_{t r}$ ) that represents the probability for a radical to propagate rather than to cause a transfer or termination reaction. In other words, one has to lower the kinetic chain length, $\lambda=\frac{1}{1-q}$. In contrast, in a poor solvent such as heptane, lowering the kinetic chain length is not sufficient to obtain soluble, individualized microgels. This is in good agreement with the results obtained by Graham on various polymerizing systems; for this author, a good solvent would be necessary to create repulsive forces between the microparticles, so that the polymer chains would present an auto-stabilizing character $[2,22,31,32]$

\section{Effect of a stabilizing comonomer}

As said before, heptane is not a sufficiently good solvent for the above composition to allow the necessary auto-stabilization. However, the use of this particular solvent would present some practical advantages over that of methylethylketone in some applications. Instead of changing the solvent, the difference in solubility parameter between solvent and polymer could also be reduced by the addition of small amounts of a well-chosen comonomer that should play the role of a "stabilizer". To verify this hypothesis, part of the amount of butyl acrylate was replaced by lauryl acrylate, LA, in the former CPM formulation. The idea was to add some long alkyl chains that would increase the overall solubility in heptane. Both 
linear copolymers and CPMs were synthesized, in order to distinguish the effects of solubility from those of crosslinking. The results are displayed in Table 4.

Linear copolymers showed rather low molar masses; they were entirely soluble in the reaction medium at $70^{\circ} \mathrm{C}$. However, all the samples with less than $7.5 \mathrm{~mol} \%$ LA led to cloudy solutions once cooled to room temperature. This confirms that LA indeed increases the solubility in heptane, and that a minimum amount is required to achieve complete miscibility with this solvent at room temperature.

At $70^{\circ} \mathrm{C}$, the presence of LA did not seem to modify any characteristics of the linear copolymers, as all the reacting systems were entirely soluble. Consequently, none of the reactions rates (initiation, propagation, transfer, termination) was altered, hence the same polymerization degree.

In contrast, increasing amounts of LA in the formulation had a strong effect on CPM characteristics. Two domains were observed: below $7.5 \mathrm{~mol} \% \mathrm{LA}$, cloudy mixtures (even at $70^{\circ} \mathrm{C}$ ), large molar masses and polydispersity indexes, and high gyration radii were obtained. Above $7.5 \mathrm{~mol} \%$, clear mixtures, low and rather constant values were measured for $\mathrm{M}_{\mathrm{w}}, \mathrm{I}_{\mathrm{p}}$ and $\mathrm{R}_{\mathrm{z}}$.

Solubility parameters can be evaluated for the different microgels based on LA, BA, CA and HDDA using Hoftyzer-Van Krevelen group contribution method [33]. As shown in Figure 6, a linear decreasing dependence of $\delta$ with $\mathrm{x}$ (LA molar fraction) is observed for the CPMs. This decrease in $\delta$ is rather small, but it is nevertheless sufficient to provide complete miscibility with heptane above a certain limit. This allows the particle auto-stabilization, whereas below this limit intermolecular reactions are more favored as particles tend to flocculate. This would tend to suggest that the influence of LA is more a surface than a bulk effect, and that this seems indeed the most important aspect to prevent particle aggregation. The phenomenon might also be emphasized by the partial deswelling of the particles once 
they are cross-linked. But in any case, the comparison between Table $3 \& 4$ shows that heptane still leads to higher molar masses, even for soluble systems.

Respective effects of the transfer agent and of the stabilizing comonomer

Linear copolymers and CPMs were synthesized from LA/BA/CA/(HDDA) (20/60[respectively 55]/20/0[respectively 5] mol\%) mixtures, using increasing amounts of RSH. The results are displayed in Table 5.

All the linear copolymers with $20 \mathrm{~mol} \%$ LA were entirely soluble in heptane at room temperature. Moreover, increasing amounts of RSH logically led to decreasing values for $\mathrm{M}_{\mathrm{n}}$, $\mathrm{M}_{\mathrm{w}}, \mathrm{I}_{\mathrm{p}}$ and $\mathrm{R}_{\mathrm{z}}$. From the $\left(D P_{n}\right)_{\text {cum }}$ values obtained for 4 samples (see Figure 7 ), it was once again possible to evaluate an average chain transfer constant for $\mathrm{RSH}$, in the same way as for pure butyl acrylate. In this case, using an average monomer concentration $[\mathrm{M}]_{0} \approx 1 \mathrm{~mol} / \mathrm{L}$, a value of $\mathrm{C}_{\mathrm{RSH}, 70^{\circ} \mathrm{C}}=0.31$ was obtained, whereas $\mathrm{C}_{\mathrm{RSH}, 70^{\circ} \mathrm{C}}=0.39$ for pure $\mathrm{BA}$. Both values are thus in good agreement.

In the case of CPMs, molar mass, polydispersity and gyration radius also decrease when $[\mathrm{RSH}]$ increases, but in a much more spectacular way as for linear copolymers. Without $\mathrm{RSH}$, macrogelation occurs, whereas for low thiol amounts, the system is obviously still very close to macrogelation, since some macroscopic particles can be observed in the reaction medium, although the system remains transparent. Therefore a minimum amount of RSH is required to avoid both macrogelation and big particles.

A comparison between the respective effects of the amounts of LA, x, and of [RSH] on the main properties of the linear polymers or CPMs is shown in Figure 8. Contrary to $\mathrm{RSH}$, the addition of LA does not modify the molar mass of the linear copolymers. Therefore in the case of CPMs, the length of the growing chains also remains the same; LA only stabilizes the particles against macrogelation by keeping them apart, thus avoiding flocculation and therefore interparticular reactions. In contrast, the transfer agent controls the 
probability for a radical to propagate, $q=\frac{r_{p}}{r_{p}+r_{t}+\Sigma r_{t r}}$, and thus the final $\left(D P_{n}\right)_{c u m}=\frac{1}{1-q}=\lambda$ (where $\lambda$ refers to the kinetic chain length). In the same way, $1 /\left(D P_{n}\right)_{\text {cum }}=1-q$ can be viewed as the probability for a radical to stop growing (by termination or transfer). This length, $\lambda$, can be estimated for linear copolymers from the values the corresponding $\left(D P_{n}\right)_{\text {cum }}$, i.e. practically from the values measured for $M_{n}$. Most of them were synthesized and their $M_{n}$ measured (see Table 5). But since the relationship found between $1 /\left(D P_{n}\right)_{\text {cum }}$ and $[R S H]$ is linear and can be written as $1 /\left(D P_{n}\right)_{c u m}=0.6339[R S H]+0.004$, values of $\left(D P_{n}\right)_{c u m}$ and $\mathrm{M}_{\mathrm{n}}$ can also be calculated for two additional linear polymers that were not synthesized: for $[R S H]=$ $0.0125 \mathrm{~mol} / \mathrm{L},\left(D P_{n}\right)_{\text {cum }}=\lambda=83.87$ and $\mathrm{M}_{\mathrm{n}}=15.5 \mathrm{~kg} / \mathrm{mol}$; and for $[R S H]=0.03 \mathrm{~mol} / \mathrm{L}$, $\left(D P_{n}\right)_{\text {cum }}=\lambda=43.45$ and $\mathrm{M}_{\mathrm{n}}=8.0 \mathrm{~kg} / \mathrm{mol}$. It is then possible to plot $\mathrm{M}_{\mathrm{w}} \mathrm{vs}$. $\lambda$ for the linear polymer series, as well as for CPMs that must have almost the same values of $\lambda$ as their linear counterpart. The resulting curves are depicted in Figure 9. It appears that while the relationship between $\mathrm{M}_{\mathrm{w}}$ and $\lambda$ is roughly proportional for linear copolymers, in the case of CPMs the mass average molar mass diverges for a critical value of kinetic chain length, $\lambda_{c}$. Above $\lambda_{c}$, macrogelation always occurs. In this particular case, $\lambda_{c}=\left(D P_{n}\right)_{c u m c}$ would be about 95. Therefore the transfer agent, RSH, allows to keep the kinetic chain length $\lambda$ below $\lambda_{c}$ and thus to avoid macrogelation, whereas the stabilizer, LA, mainly creates repulsion between the growing particles and allows to avoid flocculation and interparticular reactions. The particle auto-stabilization and the kinetic chain length (or the probability of propagation, $q$ ) are thus the essential parameters that control micro- or macrogelation: this stated, it was then interesting to vary other parameters like monomer nature, reactivity or concentration to see if the preparation of CPMs was still possible. 


\section{Effect of the CPM composition}

Several attempts were made to replace Cardura acrylate by another but more common polar monomer, namely acrylic acid, AA, while keeping heptane as the solvent. The polymerization of the system (LA/BA/AA/HDDA, 10/65/20/5 mol\%, heptane, monomers/solvent: $25 / 75 \mathrm{wt} \%,[R S H]=0.025 \mathrm{~mol} / \mathrm{L}$ ) resulted in a milky white suspension with gelled, THF-insoluble macroparticles. In contrast, another composition based on (LA/BA/AA/HDDA, 10/80/5/5 mol\%) led to a transparent CPM solution with the following characteristics: $\mathrm{M}_{\mathrm{w}}=100 \mathrm{~kg} / \mathrm{mol}, \mathrm{I}_{\mathrm{p}}=6.3 ; \mathrm{R}_{\mathrm{z}}=9.5 \mathrm{~nm} ; a=0.33$. The main difference between these two reacting systems can be found in the solubility parameter of the expected CPMs, i.e. $\delta=18.7 \mathrm{MPa}^{1 / 2}$ for the first one vs. $\delta=18.3 \mathrm{MPa}^{1 / 2}$ for the second. Keeping in mind that the system based on Cardura acrylate (LA/BA/CA/HDDA, 10/65/20/5 mol\%) also led to soluble CPMs that displayed $\delta=18.45 \mathrm{MPa}^{1 / 2}$, it can be inferred that using heptane (75 wt\%) with $[R S H]=0.025 \mathrm{~mol} / \mathrm{L}$, a threshold value exists for the solubility parameter of the desired CPMs that must have $\delta<18.5-18.6 \mathrm{MPa}^{1 / 2}$ in order to avoid macrogelation in this solvent.

\section{Effect of the overall monomer concentration}

All the above experiments were carried out using the ratio monomers/solvent $=25 / 75$ wt $\%$. Of course increasing the monomer concentration would be interesting from a practical point of view, but it should also increase the probability of intermolecular reactions. Moreover as this is done without modifying the initiator concentration, the increase in monomer concentration will lead to an increase in the propagation rate, $r_{p}$, therefore in $D P_{n} \simeq \frac{r_{p}}{r_{t}+r_{t r}}$ and $\lambda$, and it will logically be necessary to increase the amount of transfer agent in order to maintain the same result as under more dilute conditions, with an aim to keep the kinetic chain length, $\lambda$, below its critical value $\lambda_{c}$. 
In the case of CPMs, $\lambda$ can here again be estimated from the number average molar masses of the corresponding linear copolymers. Since not all of them were synthesized, an estimation can be made using the kinetic constants available for butyl acrylate [42] and the equations given in Appendix B.

For every concentration, the value of $\left(D P_{n}\right)_{\text {cum }}$ can be calculated for $\alpha=0.95$ and then used as an estimation of the kinetic chain length, $\lambda$, associated with the corresponding linear copolymer. These calculated values were then compared with those found for a series of CPMs (LA/BA/CA/HDDA, 10/65/20/5 mol\%), obtained in solution with increasing monomer concentration; the results are given in Table 6.

The transfer agent concentration, $[R S H]$, had to be adjusted accordingly in order to avoid macrogelation. When comparing the results obtained using the same $[R S H]$ but increasing values of $[M]_{0}$ (and consequently of $\lambda$ ), increasing values of $\mathrm{M}_{\mathrm{w}}$ are indeed obtained. A small increase in $\lambda$ thus results in a huge increase in $\mathrm{M}_{\mathrm{w}}$, especially as the system gets closer to the critical value, $\lambda_{c}$, above which macrogelation occurs. However, the CPMs obtained with $25 \mathrm{wt} \%$ monomers $([R S H]=0.025 \mathrm{~mol} / \mathrm{L})$ and $50 \mathrm{wt} \%$ monomers $([R S H]=0.1$ mol/L) display the same mass average molar mass, whereas the corresponding $\lambda$ values are quite different (51 vs. 29); polydispersity is also higher in the second case. Therefore $\lambda$ is not the only important parameter for the characteristics of the final system. Increasing the monomer concentration from 25 to $50 \mathrm{wt} \%$ results in dividing by 3 the overall heptane amount; under such conditions macromolecules grow much closer to one another and intermolecular reactions occur more easily, hence the increase in $\mathrm{I}_{\mathrm{p}}$.

Moreover, the increase in $[R S H]$ can end up having a non-negligible effect on the overall CPM composition. In the same way as LA, a dodecanethiol molecule brings an additional lauryl moiety to the microgel. Still comparing the samples obtained with 25 and 50 $\mathrm{wt} \%$ monomers $([R S H]=0.025$ and $0.1 \mathrm{~mol} / \mathrm{L}$, respectively $)$, it comes out that $1 / 7$ of the $\mathrm{C} 12$ 
chains are provided by RSH in the first case, whereas this proportion reaches $1 / 4$ for the more concentrated conditions with a higher RSH amount. For 100 LA units, 16 additional C12 chains are brought by RSH for the first sample, and 30 for the second; in other words, the microgels synthesized under dilute conditions contain 11.4 mol\% of $\mathrm{C} 12$ chains, whereas this amount increases to $12.6 \mathrm{~mol} \%$ for those obtained in a more concentrated medium. Therefore RSH not only limits the length of the growing chains, but also participates in the particle autostabilization process in heptane.

\section{Synthesis of polymethacrylate CPMs}

All the conclusions drawn from the above experiments were dealing with the synthesis of polyacrylate CPMs. However most of the prepared particles contained a non-negligible amount of lauryl units in order to maximize their auto-stabilizing character, especially when heptane was used as solvent. This resulted in rather soft microgels $\left(\mathrm{Tg} \approx-10^{\circ} \mathrm{C}\right)$ that, even after being thoroughly dried, flowed at room temperature. In order to obtain rigid particles, the use of other monomers, among which methyl methacrylate would obviously be the simplest and cheapest, should thus be considered.

The criteria defined to avoid macrogelation while maximizing the molar mass and crosslinking degree of polyacrylate microparticles should also apply for methacrylates. However, a first and important difference lies in their much lower reactivity. The reaction conditions had thus to be somewhat adapted to take this parameter into account. A rough estimation of the difference in reactivity between both types of monomer can be obtained by comparing the data displayed in Appendix B for butyl acrylate (Table 1B) with the corresponding results associated with butyl methacrylate (see Table 2B). According to the results, the radical polymerization of the methacrylate systems was carried out for 40 hours instead of 6 hours for acrylates, using the same reaction temperature $\left(70^{\circ} \mathrm{C}\right)$. 
A first transposition of the well-controlled reacting system (LA/BA/CA/HDDA, 20/55/20/5 mol\%, heptane, monomer/solvent: $25 / 75 \mathrm{wt} \%,[R S H]=0.025 \mathrm{~mol} / \mathrm{L})$ was then attempted simply by replacing all acrylate monomers by their methacrylate counterpart. The resulting methacrylate system (LMA/BMA/CMA/HDDMA, 20/55/20/5 mol\%) should lead to a copolymer with a lower solubility parameter, $\delta=18.00 \mathrm{MPa}^{1 / 2}$, than the corresponding acrylate combination $\left(\delta=18.35 \mathrm{MPa}^{1 / 2}\right)$. As $\delta<18.5 \mathrm{MPa}^{1 / 2}$, macrogelation should not occur and CPMs should be obtained from the radical polymerization of the methacrylate system in heptane $\left(70^{\circ} \mathrm{C}\right.$, monomers/solvent: $\left.25 / 75 \mathrm{wt} \%\right)$ using $[R S H]=0.025 \mathrm{~mol} / \mathrm{L}$. This was indeed observed, with the resulting microgels displaying $\mathrm{M}_{\mathrm{w}}=58 \mathrm{~kg} / \mathrm{mol} ; \mathrm{I}_{\mathrm{p}}=4.1$ and $a=0.40$ (polyacrylate CPMs: $\mathrm{M}_{\mathrm{w}}=101 \mathrm{~kg} / \mathrm{mol} ; \mathrm{I}_{\mathrm{p}}=4.4 ; a=0.39$ ).

Using the same experimental conditions, further attempts were then made with replacing BMA by MMA. A rapid calculation of the solubility parameters expected for these new CPMs are somewhat higher than those of the polyacrylate-based CPMs (Figure 10). Referring to this theoretical curve and to the criteria determined with polyacrylates, this means that if the synthesis must be carried out in heptane $([R S H]=0.025 \mathrm{~mol} / \mathrm{L})$, the proportion of LMA used should be over $\sim 23 \%$ in order to ensure $\delta \leq 18.5 \mathrm{MPa}^{1 / 2}$, and thus to avoid macrogelation. This was confirmed by three experiments with increasing amounts of LMA; the results are displayed in Table 7. $10 \mathrm{~mol} \%$ LMA led to macrogelation, and $20 \mathrm{~mol} \%$ to gelled macroparticles. In contrast, CPMs could be obtained from the mixture (LMA/MMA/CMA/HDDA, 30/45/20/5 mol\%) in heptane $\left(70^{\circ} \mathrm{C}\right.$, monomers/solvent: $25 \mathrm{wt} \%$, $[R S H]=0.025 \mathrm{~mol} / \mathrm{L})$. This would tend to confirm once again the threshold value, $\delta=18.5$ $\mathrm{MPa}^{1 / 2}$ below which microgels can be systematically obtained under the conditions stated above. However in this case the amount of fatty $\mathrm{C} 12$ side chains becomes so important that once again the obtained particles are soft. Therefore in order to prepare rigid CPMs, one 
definitely has to change from heptane to a better solvent in which the particle autostabilization is sufficient, without requiring the incorporation of a stabilizing co-monomer.

Experiments were thus finally run in a good solvent, methylethylketone $(\delta=19.0$ $\mathrm{MPa}^{1 / 2}$ ). Using this solvent, the radical polymerization of the system (MMA/CMA/HDDMA, $85 / 10 / 5 \mathrm{~mol} \%$ ) should allow the preparation of CPMs with an expected $\delta=18.9 \mathrm{MPa}^{1 / 2}$, and hopefully a much higher $\mathrm{Tg}$. The propagation and termination rate constants at $70^{\circ} \mathrm{C}$ being available in the literature for methyl methacrylate [42], calculations were made to evaluate the time to reach a conversion $\alpha=95 \%$ for this pure monomer in MEK under our usual experimental conditions; the results are given in Appendix B (Table 3B). It appears that about $123000 \mathrm{~s}$, or 35 hours are necessary to complete the reaction. After this time, a rigid foam was easily obtained by evaporating the solvent and could finally be ground into a powder of CPMs with a high molar mass and $\mathrm{R}_{\mathrm{z}}<100 \mathrm{~nm}$.

\section{Conclusion}

In this work, the synthesis of various polyacrylate CPMs was described using solution free radical polymerization of reacting systems based on mono- and di-functional monomers. It was shown that the preparation of solutions of nanoparticles was possible in almost any solvent, however good or bad for the growing polymer, provided that three key parameters were controlled: the monomer concentration, the parameter $q=1-\frac{1}{\left(D P_{n}\right)_{\text {cum }}}$ or the kinetic chain length, $\lambda$, and the ability of the forming particles for auto-stabilization. For any given system, it is possible to define a critical value of the kinetic chain length above which macrogelation will always occur. The first criteria for microgelation are thus directly linked to the possibility of keeping $\lambda$ below this threshold value, and this can be achieved either by 
playing on the monomer or initiator concentrations, or by the use of well-defined amounts of a transfer agent.

Moreover, even a sufficiently low value of $\lambda$ (low value of $q$ ) can still result in nonsoluble final systems if the formed nanoparticles tend to flocculate; this happens when the quality of the solvent for the growing polymer is insufficient, whereas in the case of a good solvent, some chains point out of the particles, creating repulsive forces between them and thus contributing to their auto-stabilization. This limits the extent of interparticular reactions and finally avoids macrogelation. In contrast if this phenomenon does not occur (if the solvent is not sufficiently good), then it has to be compensated for by the incorporation of stabilizing units specifically adapted for the used solvent (e.g. in our case, long alkyl units for heptane). Therefore for a given solvent, and a well-adapted value of $\lambda$, a threshold value can always be pointed out for the solubility parameter of the formed polymer, beyond which cloudy suspensions of aggregated nanoparticles are formed rather than clear solutions.

Knowing all this, for any polymerizing system it seems possible to define the experimental conditions (solvent, concentration, transfer agent...) that will allow the synthesis of true cross-linked nanoparticles solutions, even at high concentration or using less reactive monomers such as methacrylates; or when the nature of the solvent is fixed, to predict the small variation in formulation that will definitely allow the preparation of CPMs. This can be an attractive way of preparing versatile microgels to be used as functional or non-functional additives in various polymer materials or coatings.

\section{Acknowledgements}

Authors are indebted to Cray Valley, both for financial and technical support and for helpful scientific discussions. 


\section{Appendix A}

Considering $\mathrm{iPrOH}$ as a transfer agent, it can be classically written that:

$$
\left(D P_{n}\right)_{c u m}=\frac{[M]_{0}-[M]}{\frac{2 f}{1+b}\left(\left[I_{2}\right]_{0}-\left[I_{2}\right]\right)+[i P r O H]_{0}-[i P r O H]}
$$

where $[\mathrm{M}]$ and $\left[\mathrm{I}_{2}\right]$ stand for the monomer and initiator concentrations, respectively.

If $\alpha=\frac{[M]_{0}-[M]}{[M]_{0}}$ stands for conversion, then for a given conversion:

$$
\frac{1}{\left(D P_{n}\right)_{\text {cum }}}=\frac{\frac{2 f}{1+b}\left(\left[I_{2}\right]_{0}-\left[I_{2}\right]\right)+[i \mathrm{PrOH}]_{0}-[i \mathrm{PrOH}]}{\alpha[M]_{0}}=K+\frac{[i \mathrm{PrOH}]_{0}-[i \mathrm{PrOH}]}{\alpha[M]_{0}} \text { eq. } 2 \mathrm{~A}
$$

Since $\left[\mathrm{I}_{2}\right]$ depends only on $\alpha . \mathrm{K}$ is thus a constant that depends only on initiation and conversion. The propagation rate is given by:

$$
V_{p}=-\frac{d[M]}{d t}=k_{p}[M]\left[M^{\bullet}\right]
$$

and the transfer rate by:

$$
V_{t r}=-\frac{d[i \mathrm{PrOH}]}{d t}=k_{t r}\left[M^{\bullet}\right][i \mathrm{PrOH}]
$$

therefore:

$$
\frac{d[i \mathrm{PrOH}]}{[i \mathrm{PrOH}]}=\frac{k_{t r}}{k_{p}} \cdot \frac{d[M]}{[M]}=C_{i P r O H} \cdot \frac{d[M]}{[M]}
$$

and thus isopropanol concentration can be expressed as:

$$
\ln \left(\frac{[i \mathrm{PrOH}]_{0}}{[i \mathrm{PrOH}]}\right)=C_{i P r O H} \ln \left(\frac{[M]_{0}}{[M]}\right) \Rightarrow[i \mathrm{PrOH}]=[i \mathrm{PrOH}]_{0}(1-\alpha)^{C_{\text {irroH }}} \quad \text { eq. } 6 \mathrm{~A}
$$

Combining eq. $2 \mathrm{~A}$ and eq. $6 \mathrm{~A}$ results in equation 1. 


\section{Appendix B}

Using kinetic values from the literature, calculations can be made to estimate the instant, $\left(D P_{n}\right)_{i}$, and the cumulative polymerization degree, $\left(D P_{n}\right)_{c u m}$, from the conversion, $\alpha$, and the initial monomer $\left([M]_{0}\right)$ and transfer agent $\left([R S H]_{0}\right)$ concentrations, using the following equations:

$$
\begin{aligned}
& {[M]=(1-\alpha)[M]_{0}} \\
& \ln \left(\frac{[R S H]_{0}}{[R S H]}\right)=C_{R S H} \ln \left(\frac{1}{1-\alpha}\right) \\
& {\left[I_{2}\right]=\left[I_{2}\right]_{0} e^{-k_{d} t}} \\
& t=-\frac{2}{k_{d}} \ln \left(1-\frac{1}{2 k_{p}}\left(\frac{k_{d} k_{t e}}{f\left[I_{2}\right]_{0}}\right)^{1 / 2} \ln \left(\frac{1}{1-\alpha}\right)\right) \\
& \frac{1}{\left(D P_{n}\right)_{i}}=\frac{2}{1+b} \cdot \frac{\sqrt{f k_{d} k_{t e}}}{k_{p}} \cdot \frac{\left[I_{2}\right]^{1 / 2}}{[M]}+C_{R S H} \frac{[R S H]}{[M]} \\
& \left(D P_{n}\right)_{c u m}=\frac{[M]_{0}-[M]}{\frac{2 f}{1+b}\left(\left[I_{2}\right]_{0}-\left[I_{2}\right]\right)+[R S H]_{0}-[R S H]} \\
& \left(D P_{n}\right)_{c u m}=\frac{[M]_{0} \alpha}{\frac{2 f}{1+b}\left[I_{2}\right]_{0}\left(1-e^{-k_{d} t}\right)+[R S H]_{0}\left[1-(1-\alpha)^{C_{R S H}}\right]}
\end{aligned}
$$

eq. $1 \mathrm{~B}$

The values obtained for the model system, butyl acrylate at $70^{\circ} \mathrm{C}$, assuming that $\mathrm{f}=$ 0.6 and termination occurs only through disproportionation $(b=0)$, are summed up in Table 1B. The calculations were made using for $A M B N k_{d}=2.10^{-5} \mathrm{~s}^{-1}$, and for butyl acrylate $\mathrm{k}_{\mathrm{p}}=$ $13927 \mathrm{~L} \cdot \mathrm{mol}^{-1} \cdot \mathrm{s}^{-1}$ and $\mathrm{k}_{\mathrm{te}}=1 \cdot 87 \cdot 10^{8} \mathrm{~L} \cdot \mathrm{mol}^{-1} \cdot \mathrm{s}^{-1}$, i.e. values deduced from those given at $30^{\circ} \mathrm{C}$ in the literature $\left(\mathrm{k}_{\mathrm{p} 30^{\circ} \mathrm{C}}=1237 \mathrm{~L} \cdot \mathrm{mol}^{-1} \cdot \mathrm{s}^{-1}, \mathrm{k}_{\mathrm{te} 30^{\circ} \mathrm{C}}=6 \cdot 18 \cdot 10^{6} \mathrm{~L} \cdot \mathrm{mol}^{-1} \cdot \mathrm{s}^{-1}, \mathrm{E}_{\mathrm{p}}=52.3 \mathrm{~kJ} \cdot \mathrm{mol}^{-1}\right.$ and $\left.\mathrm{E}_{\mathrm{te}}=73.7 \mathrm{~kJ} \mathrm{~mol}^{-1}[42]\right)$. In this example (Table 1B), the initial monomer concentration was taken equal to that of the system (LA/BA/CA, 10/70/20 mol\%) in heptane 
(monomers/solvent: $25 / 75 \mathrm{wt} \%,[\mathrm{RSH}]=0.025 \mathrm{~mol} / \mathrm{L}$ ). The same calculations were repeated for all the studied concentrations. The value of $\mathrm{C}_{\mathrm{RSH}}$ is that determined in this work for BA at $70^{\circ} \mathrm{C}\left(\mathrm{C}_{\mathrm{RSH}}=0.39\right)$.

These calculations were made assuming a batch process. Under such conditions it appears that $\alpha=95 \%$ is reached within about $9000 \mathrm{~s}$, or 2.5 hours. Using our semi-continuous process, the monomers are added during the first 90 minutes, and the reaction is carried out for 6 hours. It is thus reasonable to consider that a conversion over $95 \%$ has been reached at the end of our process.

These calculations were repeated for the polymerization of butyl methacrylate initiated by $A M B N$ at $70^{\circ} \mathrm{C}$, using $\mathrm{k}_{\mathrm{p}}=940 \mathrm{~L} \cdot \mathrm{mol}^{-1} \cdot \mathrm{s}^{-1}$ and $\mathrm{k}_{\mathrm{te}}=1 \cdot 7 \cdot 10^{7} \mathrm{~L} \cdot \mathrm{mol}^{-1} \cdot \mathrm{s}^{-1}$, i.e. values deduced from those given at $30^{\circ} \mathrm{C}$ in the literature $\left(k_{\mathrm{p} 30^{\circ} \mathrm{C}}=362 \mathrm{~L} \cdot \mathrm{mol}^{-1} \cdot \mathrm{s}^{-1}, \mathrm{k}_{\mathrm{te} 30^{\circ} \mathrm{C}}=10 \cdot 2 \cdot 10^{6} \mathrm{~L} \cdot \mathrm{mol}^{-1} \cdot \mathrm{s}^{-}\right.$ ${ }^{1}, \mathrm{E}_{\mathrm{p}}=20.6 \mathrm{~kJ} \cdot \mathrm{mol}^{-1}$ and $\left.\mathrm{E}_{\mathrm{te}}=10.8 \mathrm{~kJ} \cdot \mathrm{mol}^{-1}[42]\right) . \mathrm{C}_{\mathrm{RSH}}$ was arbitrarily taken equal to that determined for butyl acrylate $\left(\mathrm{C}_{\mathrm{RSH}}=0.39\right)$. It appears that the time necessary to reach $\alpha=$ $95 \%$ with butyl methacrylate using a batch process at $70^{\circ} \mathrm{C}$ is roughly $48000 \mathrm{~s}$, or about 13.5 hours instead of 2.5 hours for butyl acrylate; i.e. the reaction is about six times slower. Therefore, and taking into account our semi-continuous process, we decided to carry out the radical polymerization of the methacrylate systems for 40 hours instead of 6 hours for acrylates, using the same reaction temperature $\left(70^{\circ} \mathrm{C}\right)$.

Finally, the same calculations have been made for the free radical polymerization of methyl methacrylate initiated by $\mathrm{AMBN}$ at $70^{\circ} \mathrm{C}$. The values of the various rate constants are in this case directly available from the literature [42]: $\mathrm{k}_{\mathrm{p}}=640 \mathrm{~L} \cdot \mathrm{mol}^{-1} \cdot \mathrm{s}^{-1}$ and $\mathrm{k}_{\mathrm{te}}=27 \cdot 5 \cdot 10^{6}$ L.mol ${ }^{-1} . \mathrm{s}^{-1}$. Once again $\mathrm{C}_{\mathrm{RSH}}$ was taken equal to 0.39 . 


\section{References}

1. Funke WE, Okay O, Joos-Müller B. Microgels. Intramolecularly cross-linked macromolecules with a globular structure. Adv Polym Sci 1998;136:139-234.

2. Graham NB, Cameron A. Nanogels and microgels: the new polymeric materials playground. Pure Appl Chem 1998;70:1271-1275.

3. Saunders B, Vincent B. Microgel particles as model colloids: theory, properties and applications. Adv Colloid Interface Sci 1999;80:1-25.

4. De Groot JH, Zurutuza A, Moran CR, Graham NB, Hodd KA, Norrby S. Water-soluble microgels made by radical polymerization in solution. Colloid Polym Sci 2001;279:12191224.

5. Valette L, Pascault JP, Magny B. Use of acrylic functionalized (meth)acrylic cross-linked polymer microparticles in photopolymerized acrylic films. Macromol Mater Eng 2003;288:642-657.

6. Valette L, Pascault JP, Magny B. Use of functional (meth)acrylic cross-linked polymer microparticles as toughening agents for epoxy/diamine thermosets. Macromol Mater Eng 2003;288:867-874.

7. Tobita H, Kumagai M, Aoyagi N. Microgel formation in emulsion polymerization. Polymer 2000;41:481-487.

8. Liang L, Funke WE. Crosslinking self-emulsifying copolymerization of an unsaturated polyester and styrene. Macromolecules 1996;29:8650-8655.

9. Yuan CD, Xu YS, Wang YJ, Liu DH, Chai YJ, Cao TY. Polymer microgels prepared by emulsifier-free emulsion polymerization of unsaturated polyesters and styrene. J Appl Polym Sci 2000;77:3049-3053.

10. Murray MJ, Snowden MJ. The preparation, characterization, and applications of colloidal microgels. Adv Colloid Interfac 1995;54:73-91. 
11. Antonietti M, Bremser W, Schmidt M. Microgels: model polymers for the cross-linked state. Macromolecules 1990;23:3796-3805.

12. Castelvetro V, Ciardelli F, De Vita C, Puppo A. Hybrid nanocomposite films from monoand multi-functional POSS copolyacrylates in miniemulsion. Macromol Rapid Commun 2006;27:619-625.

13. Shen S, Sudol ED, El Aasser MS. Dispersion polymerization of methyl methacrylate: mechanism of particle formation. J Polym Sci Polym Chem 1994;A32:1087-1100.

14. Takahashi K, Miyamori S, Uyama H, Kobayashi S. Preparation of micron-size monodisperse poly(2-hydroxyethyl methacrylate) particles by dispersion polymerization. $J$ Polym Sci Polym Chem 1996;A34:175-182.

15. Kiatkamjornwong S, Apiwattanon S, Rikukawa M, Ogata N. Super-fine particles of poly(styrene-co-methyl methacrylate) by dispersion copolymerization. Colloid Surface A 1999;153:229-240.

16. Jayachandran KNN, Chatterji PR. Preparation of linear and cross-linked polymer microspheres by dispersion polymerization. J Macromol Sci - Pol R 2001;C41:79-94.

17. Radhakrishnan B, Cramail H, Cloutet E. Synthesis of uniform polyurethane particles by step-growth polymerization in a dispersed medium. Colloid Polym Sci 2002;280:1122-1130.

18. Chambon P, Cloutet E, Cramail H. Synthesis of core-shell polyurethanepolydimethylsiloxane particles by polyaddition in organic dispersant media : mechanism of particle formation. Macromol Symp 2005;226:227-238.

19. Chambon P, Cloutet E, Cramail H. Synthesis of core-shell polyurethanepoly(dimethylsiloxane) particles in supercritical carbon dioxide. Macromolecules 2004;37:5856-5859. 
20. Ramanathan LS, Baskaran D, Shukla PG, Sivaram S. Preparation of polyurethane microspheres via dispersion polycondensation using poly(1,4-isoprene)-block-poly(ethylene oxide) as steric stabilizer. Macromol Chem Phys 2002;203:998-1002.

21. Staudinger H, Husemann E. Highly polymerized compounds. CXVI. The limiting swelling capability of polystyrene. Ber Deut Chem Ges 1935;68B:1618-1634.

22. Graham NB, Hayes CMG. Microgels 1: Solution polymerization using vinyl monomers. Macromol Symp 1995;93:293-300.

23. Biffis A, Graham NB, Siedlaczek G, Stalberg S, Wulff G. The synthesis, characterization and molecular recognition properties of imprinted microgels. Macromol Chem Phys 2001;202:163-171.

24. Mecerreyes D, Lee V, Hawker CJ, Hedrick JL, Wursch A, Volksen W, Magbitang T, Huang E, Miller RD. A novel approach to functionalized nanoparticles: self-crosslinking of macromolecules in ultradilute solution. Adv Mater 2001;12:204-208.

25. Harth E, Van Horn B, Lee VY, Germack DS, Gonzales CP, Miller RD, Hawker CJ. A facile approach to architecturally defined nanoparticles via intramolecular chain collapse. $J$ Am Chem Soc 2002;124:8653-8660.

26. Abrol S, Caulfield MJ, Qiao GG, Solomon DH. Studies on microgels, 5. Synthesis of microgels via living free radical polymerization. Polymer 2001;42:5987-5991.

27. Gurr PA, Qiao GG, Solomon DH, Harton SE, Spontak RJ. Synthesis, characterization, and direct observation of star microgels. Macromolecules 2003;36:5650-5654.

28. Chen H, Ishizu K, Fukutomi T, Kakurai T. Preparation of soluble microgel by the copolymerization of methylmethacrylate with p-divinylbenzene in the presence of tetrabromomethane. J Polym Sci Polym Chem Ed 1984;22:2123-2130. 
29. Ishizu K, Kuwabara S, Chen H, Mizuno H, Fukutomi T. Kinetics of crosslinking reactions. I. Reaction rate of intramolecular crosslinkings by using a soluble microgel. $J$ Polym Sci, Part A: Polym Chem 1986;24:1735-1746.

30. Frank RS, Downey JS, Yu K, Stöver HDH. Poly(divinylbenzene-alt-maleic anhydride) microgels: intermediates to microspheres and macrogels in crosslinking copolymerization. Macromolecules 2002;35:2728-2735.

31. Graham NB, Mao J. Microgels Part 2. Solution polymerization using a urethane stepgrowth mechanism. Colloids \& Surf, A: Physicochem Eng Aspects 1996;118:211-220.

32. Graham NB, Mao J, Uhrquhart A. Microgels 4: the preparation of novel microgels and their applications. Angew Makromol Chem 1996;240:113-121.

33. VanKrevelen DW. Properties of Polymers, $3^{\text {rd }}$ ed.. Amsterdam: Elsevier, 1990.

34. Petit H, Henry N, Krebs A, Uytterhoeven G, de Jong F. Ambient cure high solids acrylic resins for automotive refinish clear coat applications. Prog Org Coat 2001;43:41-49.

35. Slinckx M., Henry N, Krebs A, Uytterhoeven, G. High-solids automotive coatings. Prog Org Coat 2000;38:163-173.

36. Rosenbrand GG, Stichter H, Heymans DMC. Process for the preparation of glycidyl esters of branched carboxylic acid. US patent 6433217.

37. Van Dijk JB, Janssen PCGM, van der Ven LGJ. Analysis of coatings additives and free monomers using liquid and capillary gas chromatography. Proceedings XVIth FATIPEC Congress, 9-14 may 1982, Liège, 253-265.

38. Le Blainvaux F, Madec PJ, Maréchal E. Study of step-growth polymerizations using epoxy-carboxy reaction. Evidence of secondary reactions from model study in the bulk. Polym Bull 1985;13:237-244. 
39. Valette L, Pascault JP, Magny B. (Meth)acrylic cross-linked polymer microparticles: synthesis by dispersion polymerization and particle characterization. Macromol Mater Eng 2002;287:31-40.

40. Rouzeau S, Méchin F, Pascault JP, Magny B. Cross-linked polymer microparticles : characterization by size exclusion chromatography using universal calibration. JNPN 2006;2:53-60.

41. Nandi US, Singh M, Raghuram PVT. Chain transfer of alcohols in the polymerization of acrylic esters. Makromol Chem 1982;183:1467-1472.

42. Brandrup J, Immergut EH, Ed. Polymer Handbook, Third Edition, Section II. New York: John Wiley \& Sons, Inc., 1989. 


\section{Figure captions}

Figure 1. Chemical structure of Cardura E10 and of two byproducts

Figure 2. Synthesis of cardura acrylate

Figure 3. Mass average molar mass and polydispersity index for CPMs (CA/BA/HDDA, $20 / 75 / 5 \mathrm{~mol} \%$ ) prepared at $70^{\circ} \mathrm{C}$ in heptane/isopropanol mixtures with varying composition;

$\boldsymbol{\Delta}: \mathrm{M}_{\mathrm{w}} ; \mathbf{\square}: \mathrm{I}_{\mathrm{p}}$

Figure 4. Evaluation of the $\mathrm{iPrOH}$ chain transfer constant for the free radical polymerization of BA in heptane at $70^{\circ} \mathrm{C}$.

Figure 5. Evaluation of the RSH chain transfer constant for the free radical polymerization of BA in heptane at $70^{\circ} \mathrm{C}$.

Figure 6. Solubility parameter calculated for CPMs based on (LA/BA/CA/HDDA, x/75$\mathrm{x} / 20 / 5 \mathrm{~mol} \%$ ) for various molar fractions of LA, x (calculated by Hoftyzer - VanKrevelen method)

Figure 7. Evaluation of the average RSH chain transfer constant for the free radical polymerization of LA/BA/CA $(20 / 60 / 20)$ in heptane at $70^{\circ} \mathrm{C}$.

Figure 8. Mass average molar masses of linear copolymers and CPMs as a function of : a) LA molar fraction (LA/BA/CA x/80-x/20 mol\% or LA/BA/CA/HDDA x/75-x/20/5 mol\%, [RSH] $=0.025 \mathrm{~mol} / \mathrm{L}) ; \mathrm{b})[R S H](\mathrm{LA} / \mathrm{BA} / \mathrm{CA} 20 / 60 / 20 \mathrm{~mol} \%$ or LA/BA/CA/HDDA $20 / 55 / 20 / 5$ mol\%); heptane, $70^{\circ} \mathrm{C}$, monomers/solvent: $25 / 75 \mathrm{wt} \%$

Figure 9. Mass average molar masses of linear copolymers and CPMs as a function of kinetic chain length, $\lambda$. (LA/BA/CA/HDDA 20/60-55/20/0-5 mol\%); heptane, $70^{\circ} \mathrm{C}$, monomers/solvent: $25 / 75 \mathrm{wt} \%$. $\lambda$ was taken equal to the cumulative polymerization degree, 
$\left(\mathrm{DP}_{\mathrm{n}}\right)_{\mathrm{cum}}$, of the linear copolymers and was calculated either from the measured values of $\mathrm{M}_{\mathrm{n}}$ $([R S H]=0.01,0.02$ or $0.025 \mathrm{~mol} / \mathrm{L})$ or from the experimental linear relationship between $1 /\left(\mathrm{DP}_{\mathrm{n}}\right)_{\mathrm{cum}}$ and $[R S H]([R S H]=0.0125$ or $0.03 \mathrm{~mol} / \mathrm{L})$.

Figure 10. Solubility parameter calculated for CPMs based on polymethacrylates (LMA/MMA/CMA/HDDMA, x/75-x/20/5 mol\%). Comparison with polyacrylates (LA/BA/CA/HDDA, x/75-x/20/5 mol\%) for various molar fractions of L(M)A, x (calculated by Hoftyzer - VanKrevelen method) 
Table 1. Monomers used for the synthesis of cross-linked polymer microparticles: chemical structure and solubility parameter

\begin{tabular}{|c|c|c|c|c|}
\hline $\begin{array}{l}\text { Name \& } \\
\text { acronym } \\
\end{array}$ & Structure & $\begin{array}{c}\mathrm{M} \\
(\mathrm{g} / \mathrm{mol}) \\
\end{array}$ & $\begin{array}{c}\text { Supplier / } \\
\text { Purity } \\
\end{array}$ & $\begin{array}{c}\delta \\
(\mathrm{MPa})^{1 / 2} \\
\end{array}$ \\
\hline $\begin{array}{c}\text { Butyl acrylate, } \\
\text { BA }\end{array}$ & & 128 & $\begin{array}{l}\text { Aldrich, } \\
99 \%\end{array}$ & 18.0 \\
\hline $\begin{array}{l}\text { Lauryl acrylate, } \\
\text { LA }\end{array}$ & & 240 & $\begin{array}{c}\text { Aldrich, } \\
90 \%\end{array}$ & 17.0 \\
\hline $\begin{array}{c}\text { Cardura } \\
\text { acrylate, CA }\end{array}$ & & 300 & $\begin{array}{c}\text { Cray } \\
\text { Valley } \\
\text { (CN152), } \\
98 \%\end{array}$ & 21.3 \\
\hline $\begin{array}{c}\text { Acrylic acid, } \\
\text { AA }\end{array}$ & & 72 & $\begin{array}{c}\text { Aldrich, } \\
99 \%\end{array}$ & 24.6 \\
\hline $\begin{array}{l}\text { Hexanediol } \\
\text { diacrylate, } \\
\text { HDDA }\end{array}$ & & 226 & $\begin{array}{l}\text { Aldrich, } \\
90 \%\end{array}$ & 19.6 \\
\hline $\begin{array}{c}\text { Butyl } \\
\text { methacrylate, } \\
\text { BMA }\end{array}$ & & 142 & $\begin{array}{c}\text { Aldrich, } \\
99 \%\end{array}$ & 17.8 \\
\hline $\begin{array}{c}\text { Methyl } \\
\text { methacrylate, } \\
\text { MMA }\end{array}$ & & 100 & $\begin{array}{c}\text { Aldrich, } \\
99 \%\end{array}$ & 18.5 \\
\hline $\begin{array}{c}\text { Cardura } \\
\text { methacrylate, } \\
\text { CMA }\end{array}$ & & 314 & $\begin{array}{l}\text { Cray } \\
\text { Valley }\end{array}$ & 21.0 \\
\hline $\begin{array}{c}\text { Lauryl } \\
\text { methacrylate, } \\
\text { LMA }\end{array}$ & & 254 & $\begin{array}{c}\text { Aldrich, } \\
96 \%\end{array}$ & 17.4 \\
\hline $\begin{array}{c}\text { Hexanediol } \\
\text { dimethacrylate, } \\
\text { HDDMA }\end{array}$ & & 254 & $\begin{array}{l}\text { Cray } \\
\text { Valley }\end{array}$ & 19.1 \\
\hline
\end{tabular}


Table 2. Attempts to synthesize CPMs (CA/BA/HDDA 20/75/5 mol\%) in different solvents (monomers/solvent: $25 / 75$ wt\%)

\begin{tabular}{ccccc}
\hline solvent & $\begin{array}{c}\boldsymbol{\delta} \\
\left(\mathbf{M P a}^{\mathbf{1 / 2}}\right)\end{array}$ & aspect & $\begin{array}{c}\mathbf{M}_{\mathbf{w}}^{(\mathbf{a})} \\
(\mathbf{k g} / \mathbf{m o l})\end{array}$ & $\boldsymbol{a}^{(\mathbf{a}, \mathbf{b})}$ \\
\hline heptane & 15.1 & coagulated & - & - \\
isopropanol & 23.5 & CPM (clear) & 14 & 0.40 \\
heptane/isopropanol (50/50 wt\%) & 20.3 & CPM (clear) & 25 & 0.38 \\
methylethylketone & 19.0 & macrogel & - & - \\
\hline
\end{tabular}

a) measured by SEC-UC

b) a: Mark-Houwink-Sakurada exponent 
Table 3. Free radical polymerization of the system CA/BA/HDDA (20/75/5 mol\%) in heptane or methylethylketone $\left(70^{\circ} \mathrm{C}\right.$; solvent/monomers: $\left.75 / 25 \mathrm{wt} \%\right)$ using iPrOH or $\mathrm{RSH}$ (0.025 $\mathrm{mol} / \mathrm{L})$ as transfer agent

\begin{tabular}{ccccccc}
\hline solvent & $\begin{array}{c}\boldsymbol{\delta}_{\text {solvent }} \\
\left(\mathbf{M P a}^{\mathbf{1 / 2}}\right)\end{array}$ & $\begin{array}{c}\text { final } \\
\mathbf{a s p e c t}\end{array}$ & $\begin{array}{c}\mathbf{M}_{\mathbf{w}}^{\mathbf{a})} \\
(\mathbf{k g} / \mathbf{m o l})\end{array}$ & $\mathbf{I}_{\mathbf{p}}^{\mathbf{a})}$ & $\mathbf{R}_{\mathbf{z}}(\mathbf{n m})^{\mathbf{a})}$ & $\boldsymbol{a}^{\mathbf{a})}$ \\
\hline heptane/iPrOH 50/50wt\% & 20.3 & clear & 25 & 2.6 & 5.0 & 0.38 \\
methylethylketone + RSH & 19.0 & clear & 26.5 & 2.3 & 5.5 & 0.42 \\
heptane + RSH & 15.1 & cloudy & 775 & 47 & 31.0 & 0.35 \\
\hline
\end{tabular}

a) from SEC-UC measurements; $a$ : Mark-Houwink-Sakurada exponent 
Table 4. Synthesis of linear copolymers (LA/BA/CA, $x / 80-x / 20$ mol\%) and of the corresponding CPMs (LA/BA/CA/HDDA, x/75-x/20/5 mol\%) in heptane + RSH $(0.025$ mol/L) at $70^{\circ} \mathrm{C}$ (solvent/ monomers: $\left.75 / 25 w t \%\right)$

\begin{tabular}{|c|cccc|cccc|}
\hline \multirow{2}{*}{$\% \mathbf{L A}, \mathbf{x}$} & \multicolumn{3}{|c|}{ Linear copolymers } & \multicolumn{4}{c|}{ CPMs } \\
\cline { 2 - 8 } & $\begin{array}{c}\text { final } \\
\text { aspect }\end{array}$ & $\begin{array}{c}\mathbf{M}_{\mathbf{w}}{ }^{\mathbf{a})} \\
(\mathbf{k g} / \mathbf{m o l})\end{array}$ & $\mathbf{I}_{\mathbf{p}}^{\mathbf{a})}$ & $\mathbf{R}_{\mathbf{z}}{ }^{\mathbf{a})}(\mathbf{n m})$ & $\begin{array}{c}\text { final } \\
\text { aspect }\end{array}$ & $\begin{array}{c}\mathbf{M}_{\mathbf{w}}{ }^{\mathbf{a})} \\
(\mathbf{k g} / \mathbf{m o l})\end{array}$ & $\mathbf{I}_{\mathbf{p}}{ }^{\mathbf{a})}$ & $\mathbf{R}_{\mathbf{z}}{ }^{\mathbf{a})}(\mathbf{n m})$ \\
\hline 0 & clear & 16.5 & 1.7 & 4.5 & cloudy & 775 & 47 & 31.0 \\
2.5 & clear & 16.0 & 1.8 & 4.2 & cloudy & 123 & 7.9 & 11.4 \\
5.0 & clear & 16.0 & 1.8 & 4.2 & cloudy & 272 & 11.8 & 16.2 \\
7.5 & clear & 16.5 & 1.7 & 4.2 & clear & 82 & 5.9 & 9.0 \\
10.0 & clear & 16.5 & 1.7 & 4.2 & clear & 124 & 7.5 & 11.0 \\
20.0 & clear & 15.5 & 1.6 & 4.0 & clear & 101 & 4.4 & 9.6 \\
\hline
\end{tabular}

a) determined by SEC-UC 
Table 5. Synthesis of linear copolymers and CPMs with varying amounts of transfer agent, RSH. Formulation: LA/BA/CA/HDDA, 20/60[55]/20/0[5] mol\%, heptane, $70^{\circ} \mathrm{C}$, solvent/monomers: $75 / 25$ wt\%

\begin{tabular}{|c|c|c|c|c|c|c|c|c|c|}
\hline \multirow{2}{*}{$\begin{array}{l}{[\mathrm{RSH}]} \\
(\mathrm{mol} / \mathrm{L})\end{array}$} & \multicolumn{5}{|c|}{ Linear copolymers } & \multicolumn{4}{|l|}{ CPMs } \\
\hline & $\begin{array}{c}\text { Final } \\
\text { aspect }\end{array}$ & $\begin{array}{c}\mathbf{M}_{\mathrm{n}}^{\mathrm{a})} \\
(\mathrm{kg} / \mathrm{mol})\end{array}$ & $\begin{array}{c}\mathbf{M}_{\mathrm{w}}^{\mathrm{a})} \\
(\mathrm{kg} / \mathrm{mol})\end{array}$ & $\mathbf{I}_{\mathbf{p}}{ }^{\mathbf{a})}$ & $\begin{array}{l}\mathbf{R}_{\mathbf{z}}{ }^{\mathrm{a})} \\
(\mathbf{n m})\end{array}$ & Final aspect & $\begin{array}{c}\mathbf{M}_{\mathrm{w}}^{\mathrm{a})} \\
(\mathrm{g} / \mathrm{mol})\end{array}$ & $\mathbf{I}_{\mathbf{p}}{ }^{\mathbf{a})}$ & $\begin{array}{l}\mathbf{R}_{\mathbf{z}}{ }^{\mathrm{a})} \\
(\mathbf{n m})\end{array}$ \\
\hline 0 & clear & 51.5 & 357 & 6.9 & 25 & macrogel & - & - & - \\
\hline 0.010 & clear & 17.0 & 34 & 2.0 & 6.3 & clear+some macroparticles & 950 & 40 & 34.0 \\
\hline 0.0125 & - & $15.5^{\mathrm{b})}$ & - & - & - & clear+some macroparticles & 565 & 27 & 24.5 \\
\hline 0.020 & clear & 11.0 & 19 & 1.7 & 4.5 & clear & 165 & 8 & 12.8 \\
\hline 0.025 & clear & 9.5 & 15.5 & 1.6 & 4.0 & clear & 101 & 4.4 & 9.6 \\
\hline 0.030 & - & $8.0^{\mathrm{b})}$ & - & - & - & clear & 44.5 & 2.7 & 6.8 \\
\hline
\end{tabular}

a) from SEC-UC

b) these samples were not synthesized; $\mathrm{M}_{\mathrm{n}}$ was calculated from the linear relationship between $[R S H]$ and $1 /\left(D P_{n}\right)_{c u m}$ 
Table 6. Synthesis of CPMs (LA/BA/CA/HDDA, 10/65/20/5 mol \%) in heptane $\left(70^{\circ} \mathrm{C}\right)$ using increasing monomer concentrations. [RSH] was adjusted accordingly in order to avoid macrogelation.

\begin{tabular}{cccc|ccc}
\hline $\begin{array}{c}\text { Monomer } \\
\mathbf{w t} \%\end{array}$ & $\begin{array}{c}{[\mathbf{M}]_{\mathbf{o}}} \\
\mathbf{m o l} / \mathbf{L}\end{array}$ & $\begin{array}{c}{[\mathbf{R S H}]} \\
\mathbf{m o l} / \mathbf{L}\end{array}$ & $\frac{[\boldsymbol{M}]_{\mathbf{0}}}{[\boldsymbol{R S H}]}$ & $\lambda^{\mathbf{a})}$ & $\begin{array}{c}\mathbf{M}_{\mathbf{w}}^{\mathbf{b})} \\
(\mathbf{k g} / \mathbf{m o l})\end{array}$ & $\mathbf{I}_{\mathbf{p}}^{\mathbf{b})}$ \\
\hline 25 & 1.025 & 0.025 & 41 & 51 & 124 & 7.5 \\
30 & 1.25 & 0.025 & 50 & 62 & 287 & 12.8 \\
33 & 1.35 & 0.05 & 27 & 35 & 88.5 & 6.3 \\
40 & 1.70 & 0.05 & 34 & 44 & 487 & 19.1 \\
50 & 2.15 & 0.10 & 21.5 & 29 & 127 & 9.1 \\
\hline
\end{tabular}

a) calculated from $\left(\mathrm{DP}_{\mathrm{n}}\right)_{\mathrm{cum}}(\alpha=95 \%)$ using equations 1B-6B for the corresponding linear copolymer (see also Table 1B)

b) determined by SEC-UC 
Table 7. Free radical polymerization of the system LMA/MMA/CMA/HDDMA (x/75-x/20/5 mol\%) in heptane $\left(70^{\circ} \mathrm{C}\right.$; solvent/monomers: $75 / 25$ wt\%) using $\mathrm{RSH}(0.025 \mathrm{~mol} / \mathrm{L})$ as transfer agent

\begin{tabular}{ccccccc}
\hline $\begin{array}{c}\text { \% } \\
\mathbf{L M A}\end{array}$ & $\begin{array}{c}\boldsymbol{\delta}_{\mathbf{C P M s}} \\
\left(\mathbf{M P a}^{\mathbf{1} / 2}\right)\end{array}$ & final aspect & $\begin{array}{c}\mathbf{M}_{\mathbf{w}}^{\mathbf{a})} \\
(\mathbf{k g} / \mathbf{m o l})\end{array}$ & $\mathbf{I}_{\mathbf{p}}^{\mathbf{a})}$ & $\mathbf{R}_{\mathbf{z}}(\mathbf{n m})^{\mathbf{a})}$ & $\boldsymbol{a}^{\mathbf{a})}$ \\
\hline 10 & 18.75 & macrogel & - & - & - & - \\
20 & 18.60 & macroscopic coagulated particles & - & - & - & - \\
30 & 18.40 & cloudy & 114 & 7.1 & 10 & 0.36 \\
\hline
\end{tabular}

a) from SEC-UC measurements; $a$ : Mark-Houwink-Sakurada exponent 
Table 1B. Concentrations and polymerization degrees as a function of conversion. The values were calculated for the free radical polymerization of butyl acrylate at $70^{\circ} \mathrm{C}$, using

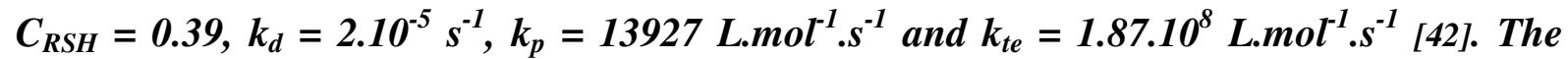
initial monomer concentration was taken equal to the overall monomer concentration of the system (LA/BA/CA, 10/70/20 mol\%) in heptane (monomers/solvent: 25/75 wt\%, [RSH] $=0.025 \mathrm{~mol} / \mathrm{L}$ ).

\begin{tabular}{ccccccc}
\hline$\alpha$ & $\begin{array}{c}{[\mathbf{M}]} \\
(\mathbf{m o l} / \mathbf{L})\end{array}$ & $\begin{array}{c}{[\mathbf{R S H}]} \\
(\mathbf{m o l} / \mathbf{L})\end{array}$ & $\begin{array}{c}{\left[\mathbf{I}_{2}\right]} \\
(\mathbf{m o l} / \mathbf{L})\end{array}$ & $\mathbf{t}(\mathbf{s})$ & $\left(\mathbf{D P}_{\mathbf{n}}\right)_{\mathbf{i}}$ & $\left(\mathbf{D P}_{\mathbf{n}}\right)_{\mathbf{c u m}}$ \\
\hline 0.00 & 1.05 & 0.0250 & 0.01000 & 0 & 101 & 101 \\
0.20 & 0.84 & 0.0229 & 0.00987 & 635 & 87 & 94 \\
0.40 & 0.63 & 0.0205 & 0.00971 & 1459 & 73 & 86 \\
0.60 & 0.42 & 0.0175 & 0.00949 & 2632 & 56 & 78 \\
0.80 & 0.21 & 0.0133 & 0.00911 & 4669 & 36 & 66 \\
0.95 & 0.0525 & 0.0078 & 0.00837 & 8874 & 14 & 52 \\
\hline
\end{tabular}


Table 2B. Concentrations and polymerization degrees as a function of conversion. The values were calculated for the free radical polymerization of butyl methacrylate at $70^{\circ} \mathrm{C}$,

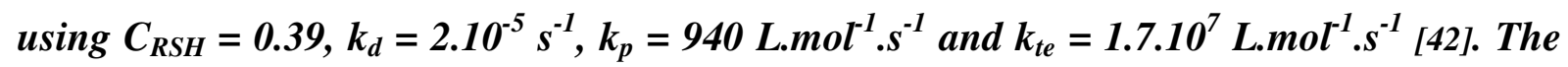
initial monomer concentration was taken equal to the overall monomer concentration of the system (LMA/BMA/CMA/HDDMA, 20/55/20/5 mol\%) in heptane (monomers/solvent: $25 / 75 w t \%,[R S H]=0.025 \mathrm{~mol} / \mathrm{L})$.

\begin{tabular}{ccccccc}
\hline$\alpha$ & $\begin{array}{c}{[\mathbf{M}]} \\
(\mathbf{m o l} / \mathbf{L})\end{array}$ & $\begin{array}{c}{[\mathbf{R S H}]} \\
(\mathbf{m o l} / \mathbf{L})\end{array}$ & $\begin{array}{c}{\left[\mathbf{I}_{\mathbf{2}}\right]} \\
(\mathbf{m o l} / \mathbf{L})\end{array}$ & $\mathbf{t}(\mathbf{s})$ & $\left(\mathbf{D P}_{\mathbf{n}}\right)_{\mathbf{i}}$ & $(\mathbf{D P})_{\mathbf{c u m}}$ \\
\hline 0.00 & 0.880 & 0.0250 & 0.01000 & 0 & 69 & 69 \\
0.20 & 0.704 & 0.0229 & 0.00944 & 2866 & 59 & 64 \\
0.40 & 0.528 & 0.0205 & 0.00875 & 6687 & 49 & 58 \\
0.60 & 0.352 & 0.0175 & 0.00781 & 12332 & 37 & 52 \\
0.80 & 0.176 & 0.0133 & 0.00634 & 22789 & 23 & 44 \\
0.95 & 0.044 & 0.0078 & 0.00385 & 47694 & 9 & 34 \\
\hline
\end{tabular}


Table 3B. Concentrations and polymerization degrees as a function of conversion. The values were calculated for the free radical polymerization of methyl methacrylate at $70^{\circ} \mathrm{C}$, using $C_{R S H}=0.39, k_{d}=2.10^{-5} \mathrm{~s}^{-1}, k_{p}=640 \mathrm{L.mol}^{-1} . \mathrm{s}^{-1}$ and $k_{t e}=27.5 .10^{6} \mathrm{~L}_{\mathrm{mol}} \mathrm{m}^{-1} \mathrm{~s}^{-1}$ [42]. The initial monomer concentration was taken equal to the overall monomer concentration of the system (MMA/CMA/HDDMA, 85/10/5 mol\%) in methylethylketone (monomers/solvent: $25 / 75 \mathrm{wt} \%,[\mathrm{RSH}]=0.025 \mathrm{~mol} / \mathrm{L})$.

\begin{tabular}{ccccccc}
\hline$\alpha$ & $\begin{array}{c}{[\mathbf{M}]} \\
(\mathbf{m o l} / \mathbf{L})\end{array}$ & $\begin{array}{c}{[\mathbf{R S H}]} \\
(\mathbf{m o l} / \mathbf{L})\end{array}$ & $\begin{array}{c}{\left[\mathbf{I}_{2}\right]} \\
(\mathbf{m o l} / \mathbf{L})\end{array}$ & $\mathbf{t}(\mathbf{s})$ & $\left(\mathbf{D P}_{\mathbf{n}}\right)_{\mathbf{i}}$ & $(\mathbf{D P})_{\mathbf{c u m}}$ \\
\hline 0.00 & 1.590 & 0.0250 & 0.01000 & 0 & 103 & 103 \\
0.20 & 1.272 & 0.0229 & 0.00897 & 5423 & 89 & 96 \\
0.40 & 0.954 & 0.0205 & 0.00773 & 12877 & 73 & 88 \\
0.60 & 0.636 & 0.0175 & 0.00614 & 24428 & 56 & 79 \\
0.80 & 0.318 & 0.0133 & 0.00384 & 47915 & 36 & 67 \\
0.95 & 0.0795 & 0.0078 & 0.00085 & 123304 & 17 & 54 \\
\hline
\end{tabular}


Figure 1. Chemical structure of Cardura E10 and of two byproducts<smiles>CCCCCCC(C)(C)C(=O)OCC1CO1</smiles><smiles>CCCCCCC(C)(C)C(=O)OCC(O)CO</smiles><smiles>CCCCCCC(C)(C)C(=O)OCC(O)COC(=O)C(C)(C)CCCCCC</smiles> 
Figure 2. Synthesis of cardura acrylate

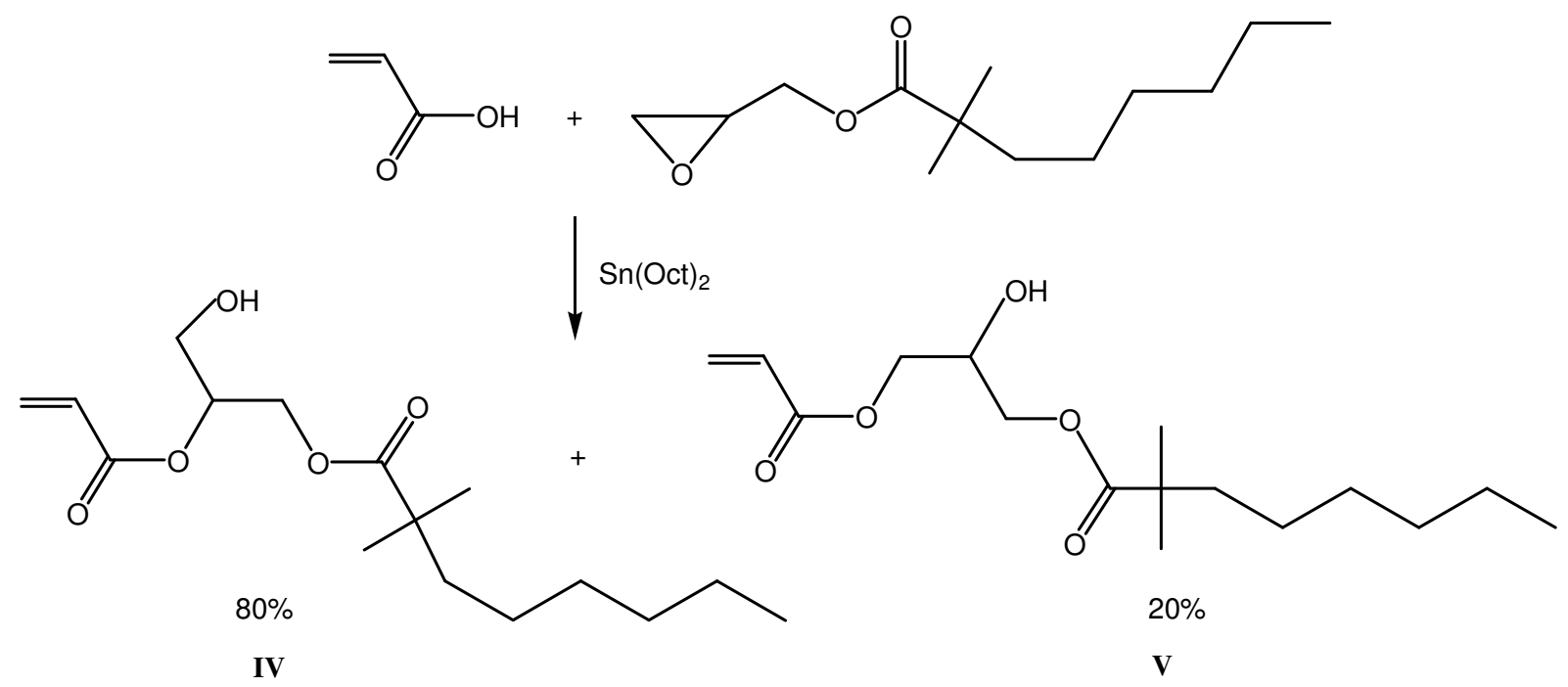


Figure 3. Mass average molar mass and polydispersity index for CPMs (CA/BA/HDDA, 20/75/5 mol\%) prepared at $70^{\circ} \mathrm{C}$ in heptane/isopropanol mixtures with varying composition; $\boldsymbol{\Lambda}: M_{w} ; \boldsymbol{\Xi}: I_{p}$.

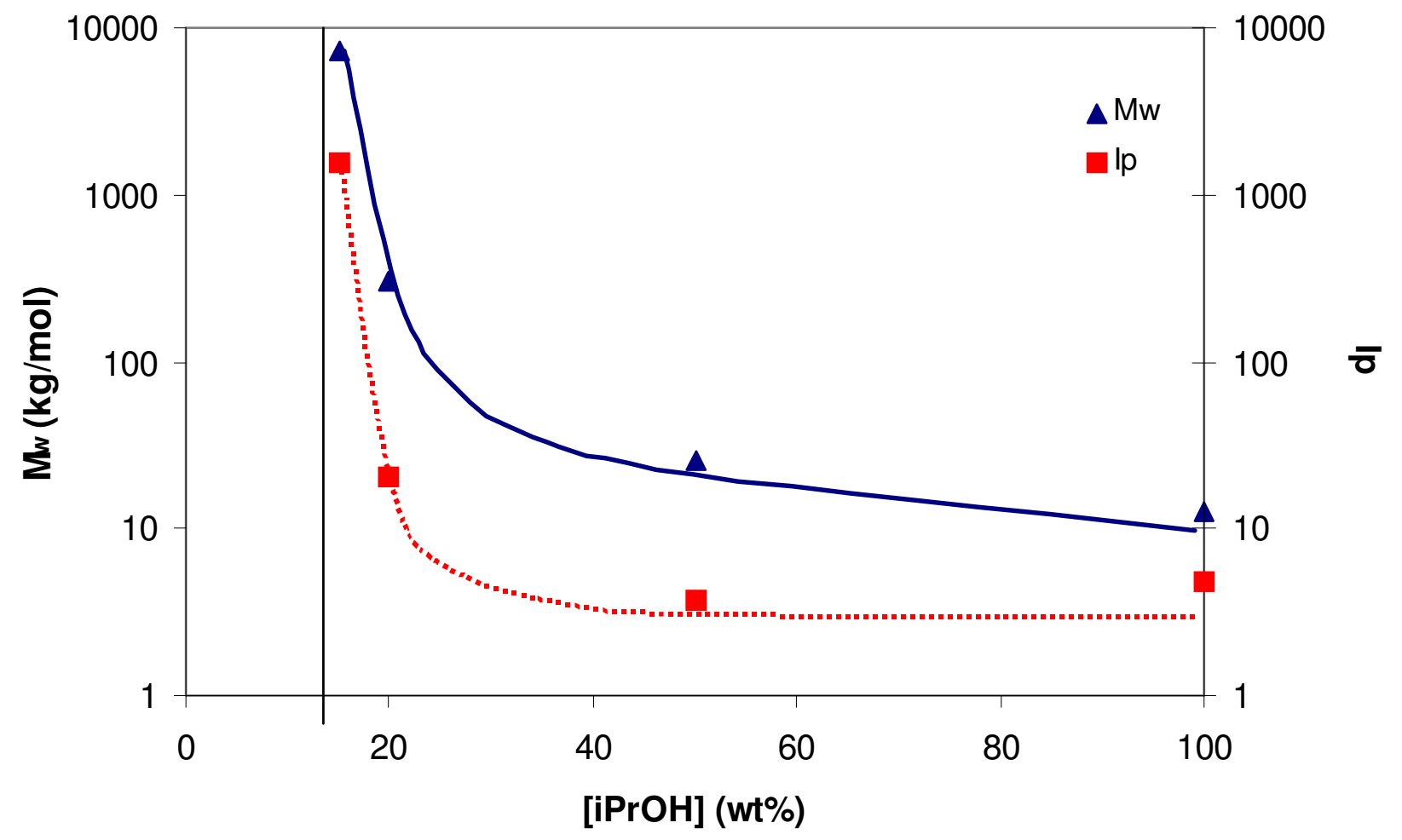


Figure 4. Evaluation of the $\mathrm{iPrOH}$ transfer rate constant for the free radical polymerization of $B A$ in heptane at $70^{\circ} \mathrm{C}$.

\section{$1 /\left(D P_{n}\right)_{\text {cum }}$}

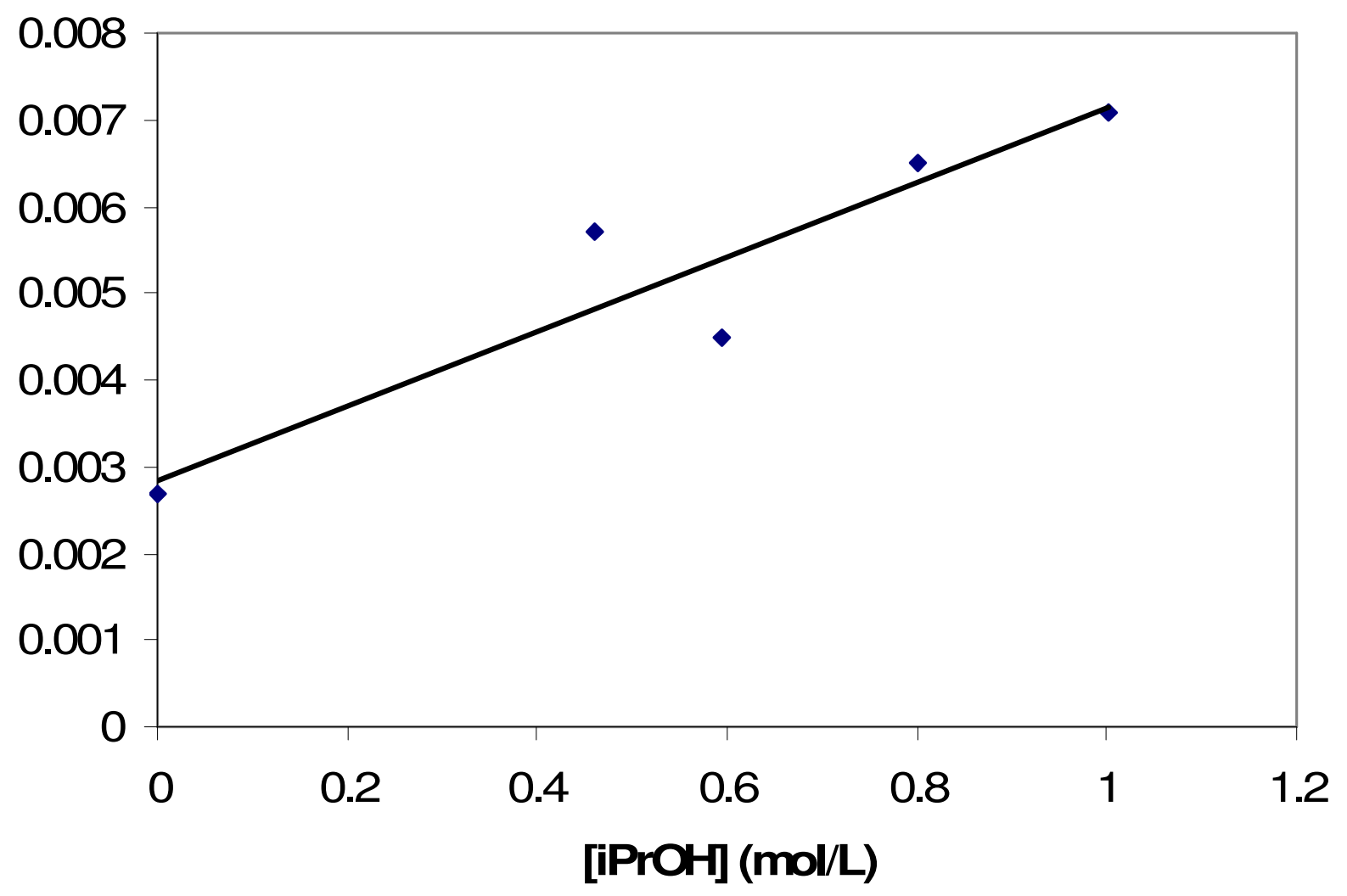


Figure 5. Evaluation of the RSH transfer rate constant for the free radical polymerization of $B A$ in heptane at $70^{\circ} \mathrm{C}$.

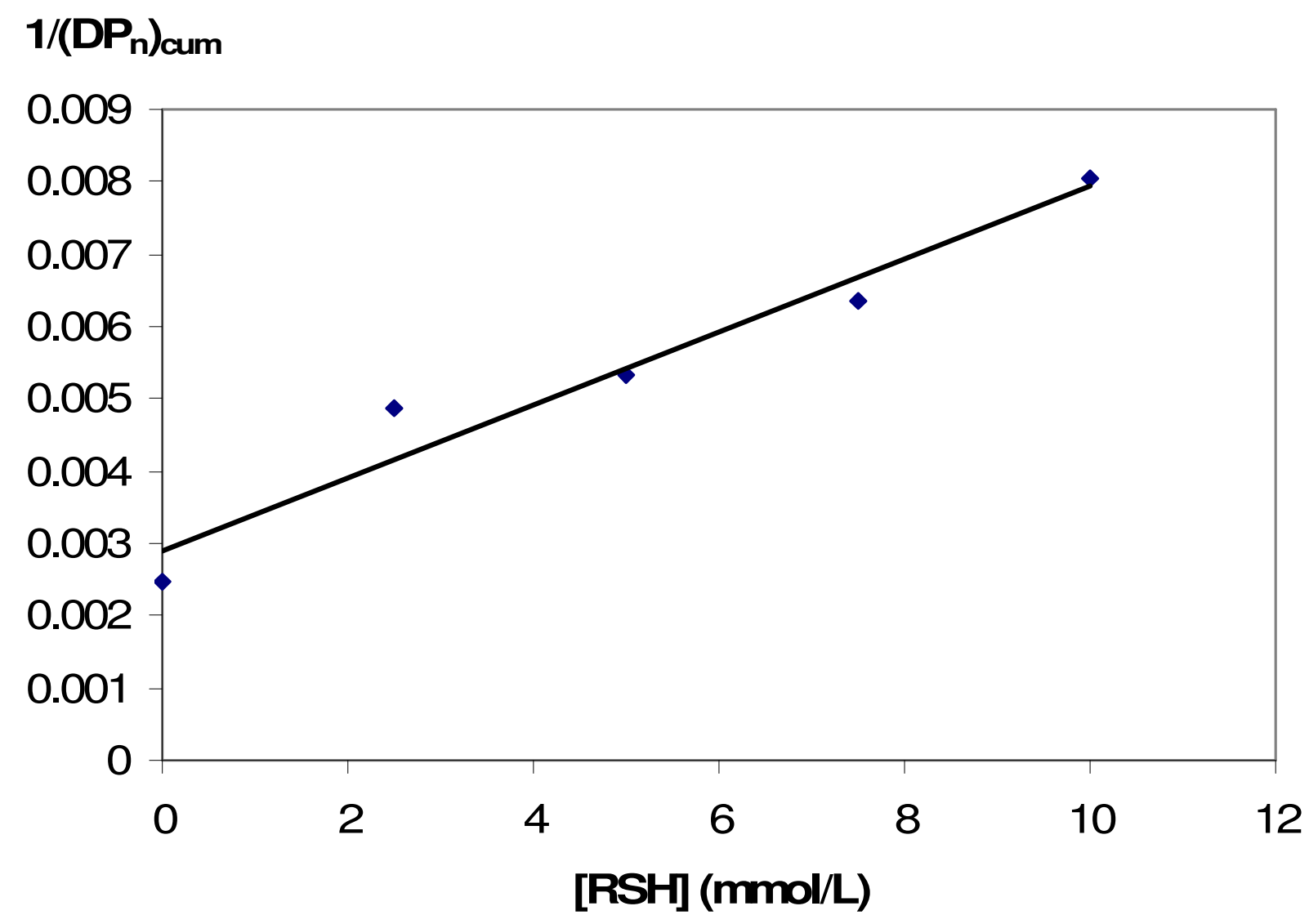


Figure 6. Solubility parameter calculated for CPMs based on (LA/BA/CA/HDDA, $x / 75$ $x / 20 / 5$ mol\%) for various molar fractions of LA, $x$ (calculated by Hoftyzer - VanKrevelen method)

\section{$\delta\left(\mathrm{MPa}^{1 / 2}\right)$}

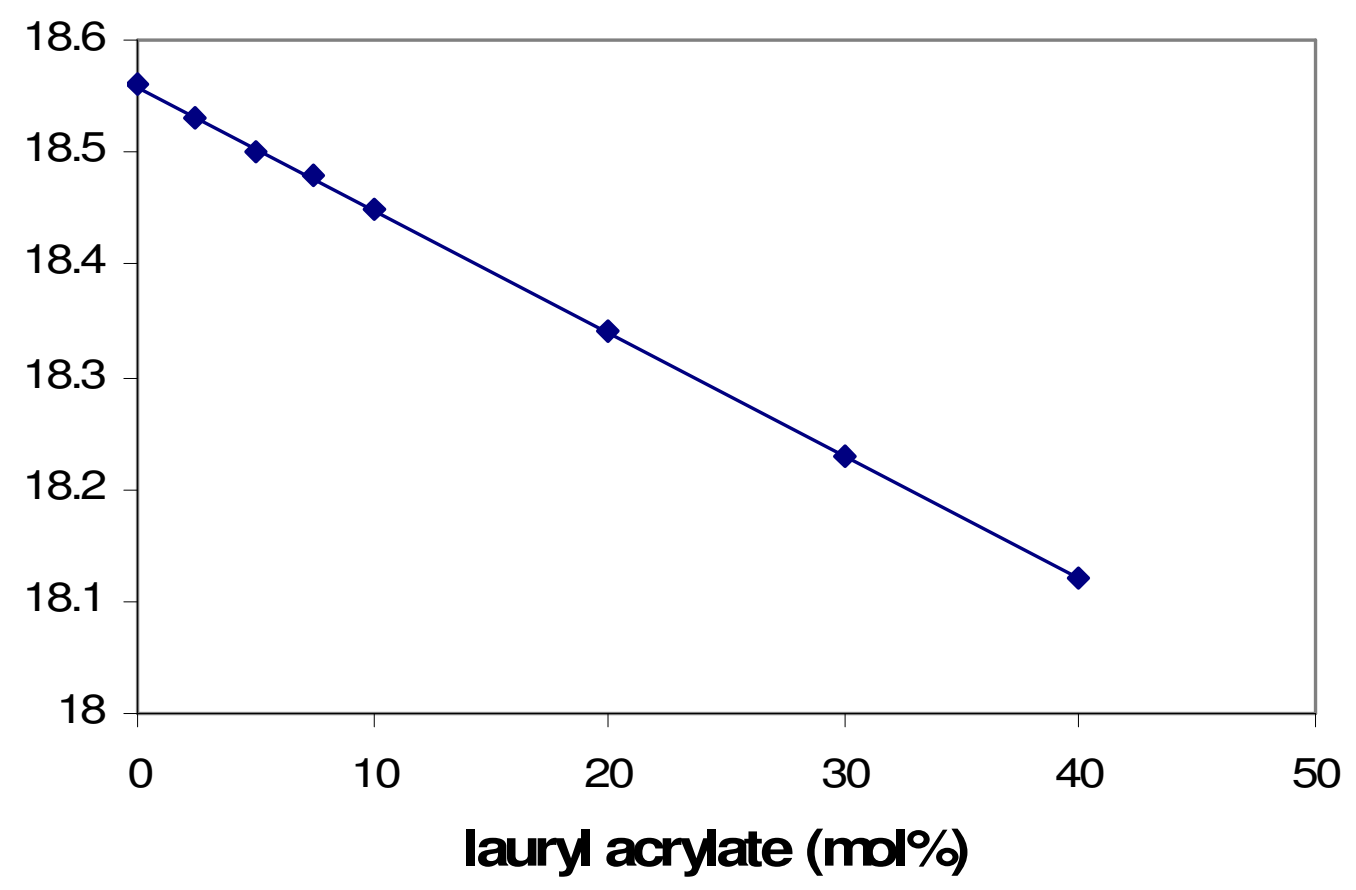


Figure 7. Evaluation of the $\mathrm{RSH}$ transfer rate constant for the free radical polymerization of LA/BA/CA (20/60/20) in heptane at $70^{\circ} \mathrm{C}$.

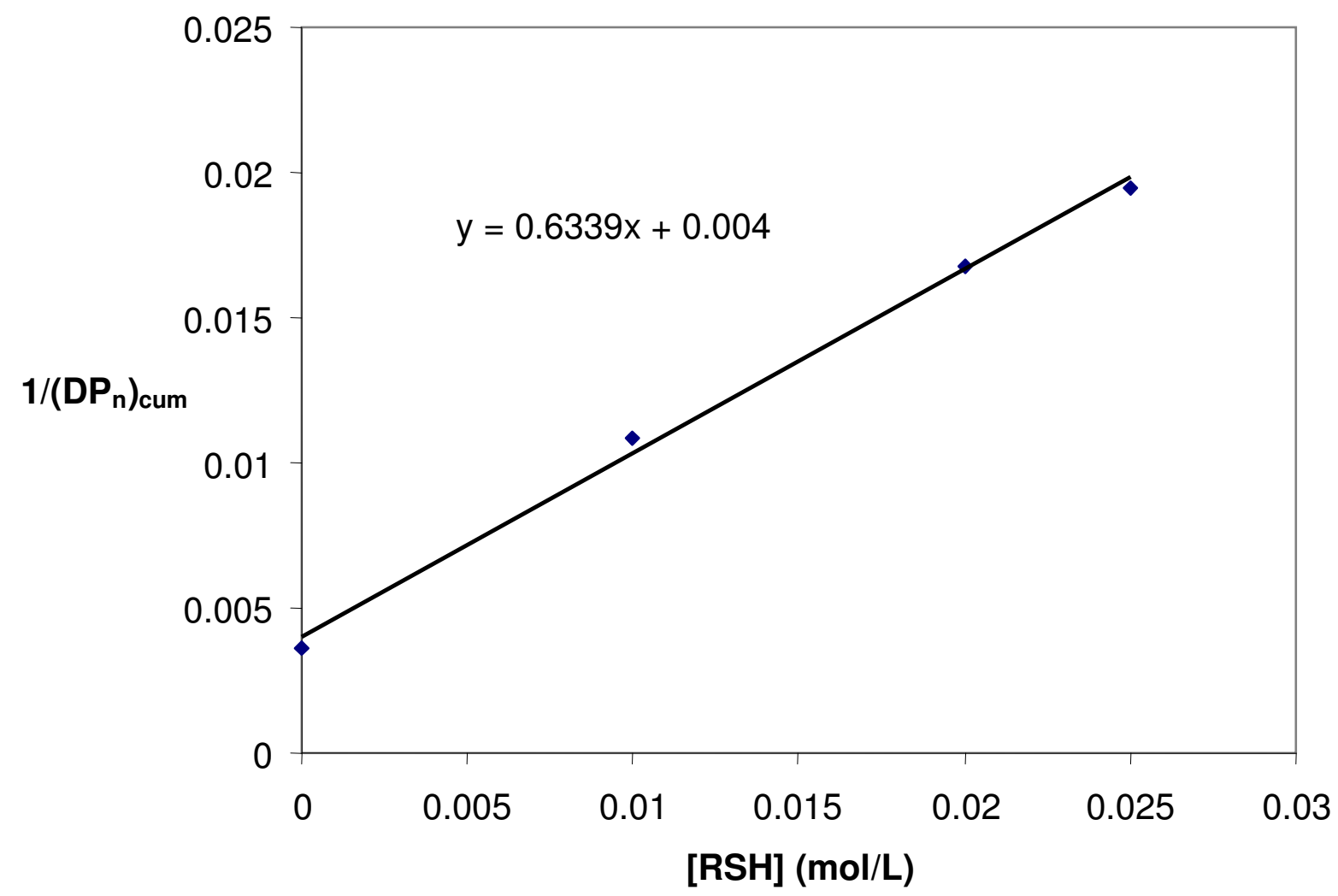


Figure 8. Mass average molar masses of linear copolymers and CPMs as a function of : a) $L A$ molar fraction (LA/BA/CA $x / 80-x / 20$ mol\% or LA/BA/CA/HDDA $x / 75-x / 20 / 5$ mol\%, $[R S H]=0.025 \mathrm{~mol} / \mathrm{L}) ; \mathrm{b})[\mathrm{RSH}](\mathrm{LA} / \mathrm{BA} / \mathrm{CA} 20 / 60 / 20 \mathrm{~mol} \%$ or LA/BA/CA/HDDA 20/55/20/5 mol\%); heptane, $70^{\circ} \mathrm{C}$, monomers/solvent: $25 / 75 \mathrm{wt} \%$

a)

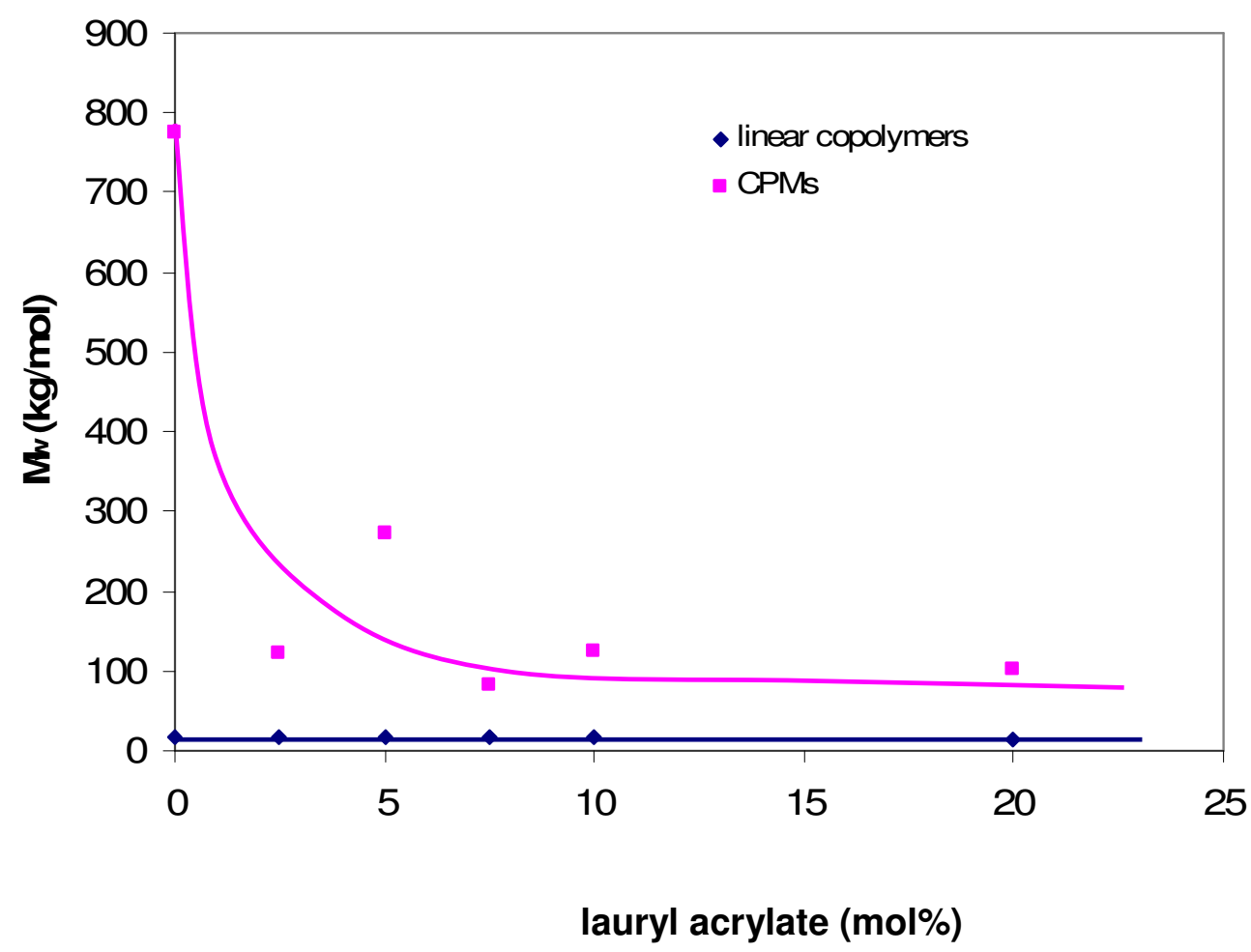

b) 


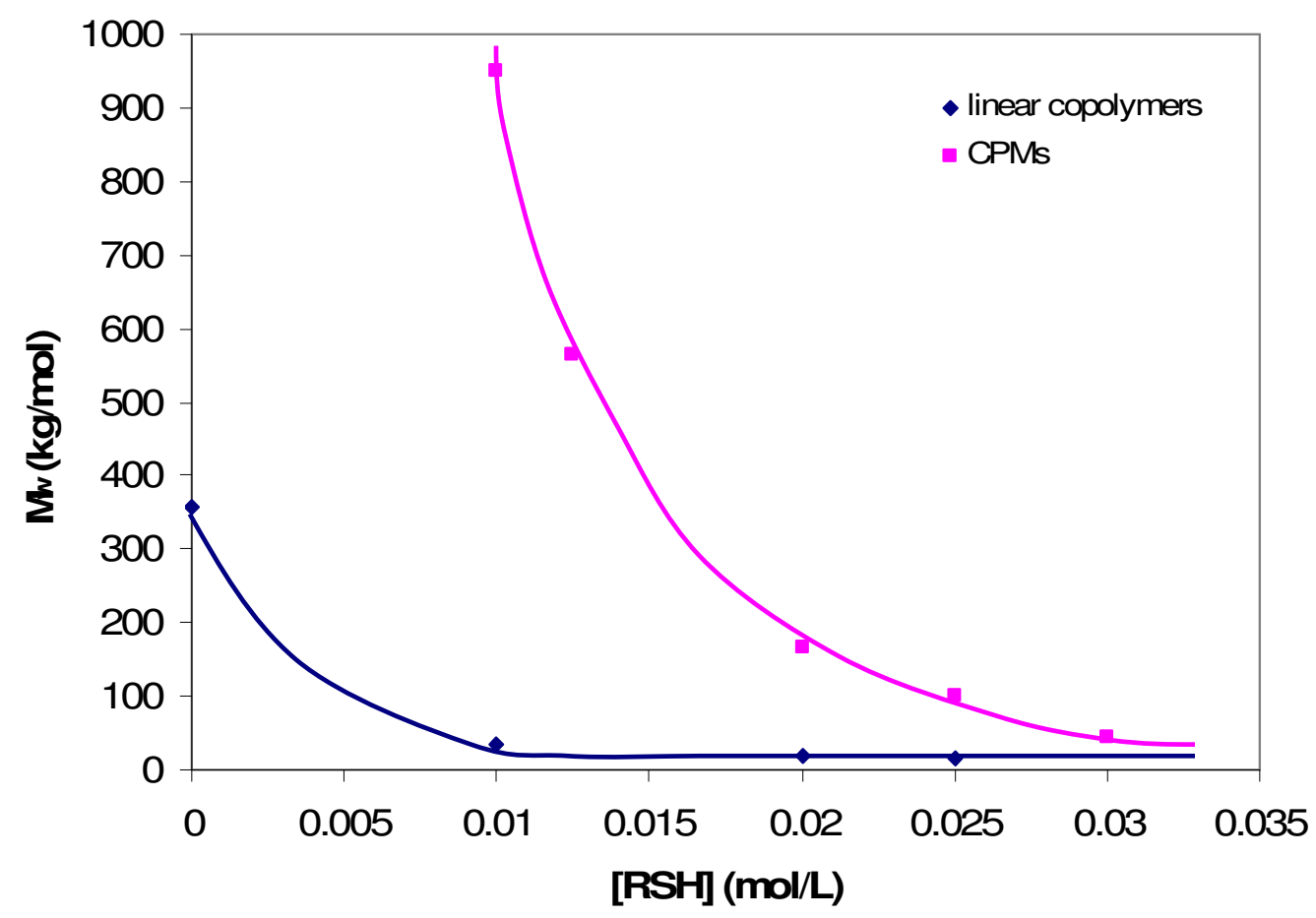


Figure 9. Mass average molar masses of linear copolymers and CPMs as a function of kinetic chain length, $\square .\left(L A / B A / C A / H D D A ~ 20 / 60-55 / 20 / 0-5\right.$ mol\%); heptane, $70^{\circ} \mathrm{C}$, monomers/solvent: $25 / 75 \mathrm{wt} \%$. $\square$ was taken equal to the final cumulated polymerization degree, $\left(D P_{n}\right)_{c u m}$, of the linear copolymers and was calculated either from the measured values of $M_{n}([R S H]=0.01,0.02$ or $0.025 \mathrm{~mol} / \mathrm{L})$ or from the experimental linear relationship between $1 /\left(\mathrm{DP}_{n}\right)_{\text {cum }}$ and $[\mathrm{RSH}]([\mathrm{RSH}]=0.0125 \mathrm{or} 0.03 \mathrm{~mol} / \mathrm{L})$.

\section{$\mathrm{M}_{\mathrm{w}}(\mathrm{kg} / \mathrm{mol})$}

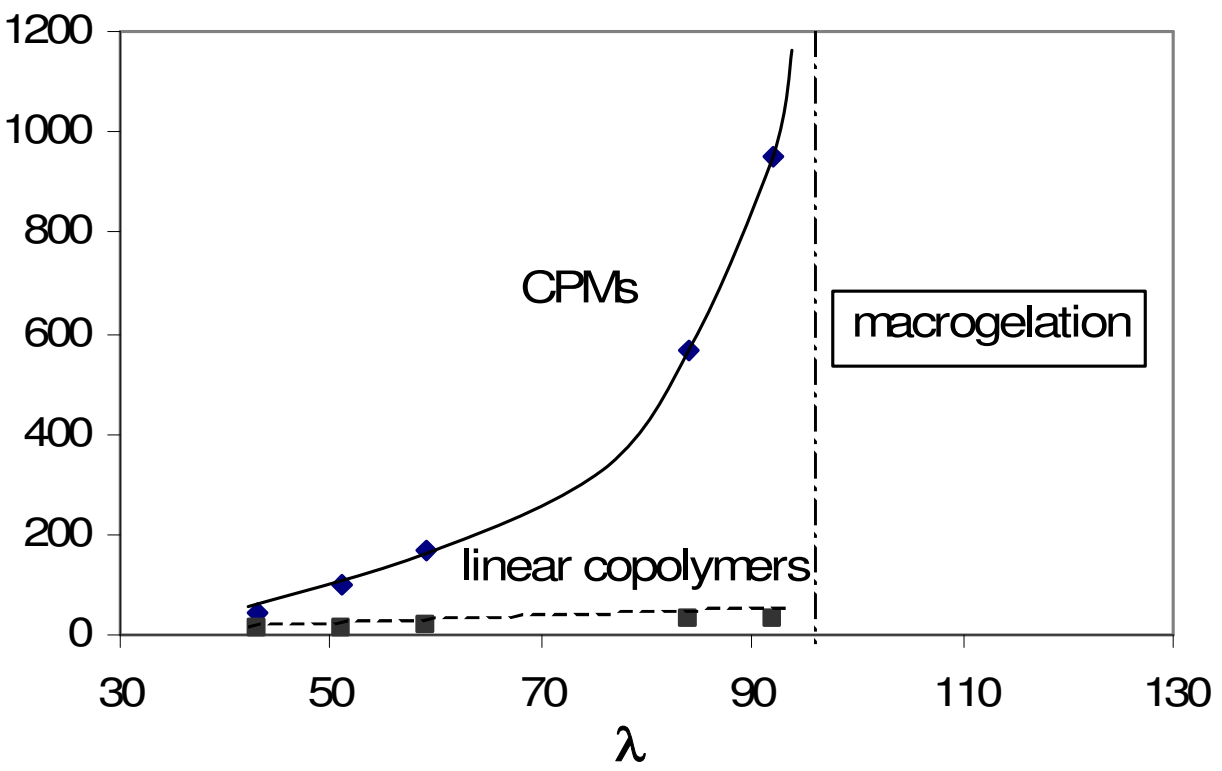


Figure 10. Solubility parameter calculated for CPMs based on polymethacrylates (LMA/MMA/CMA/HDDMA, $x / 75-x / 20 / 5$ mol\%). Comparison with polyacrylates (LA/BA/CA/HDDA, $x / 75-x / 20 / 5$ mol\%) for various molar fractions of $L(M) A, x$ (calculated by Hoftyzer - VanKrevelen method)

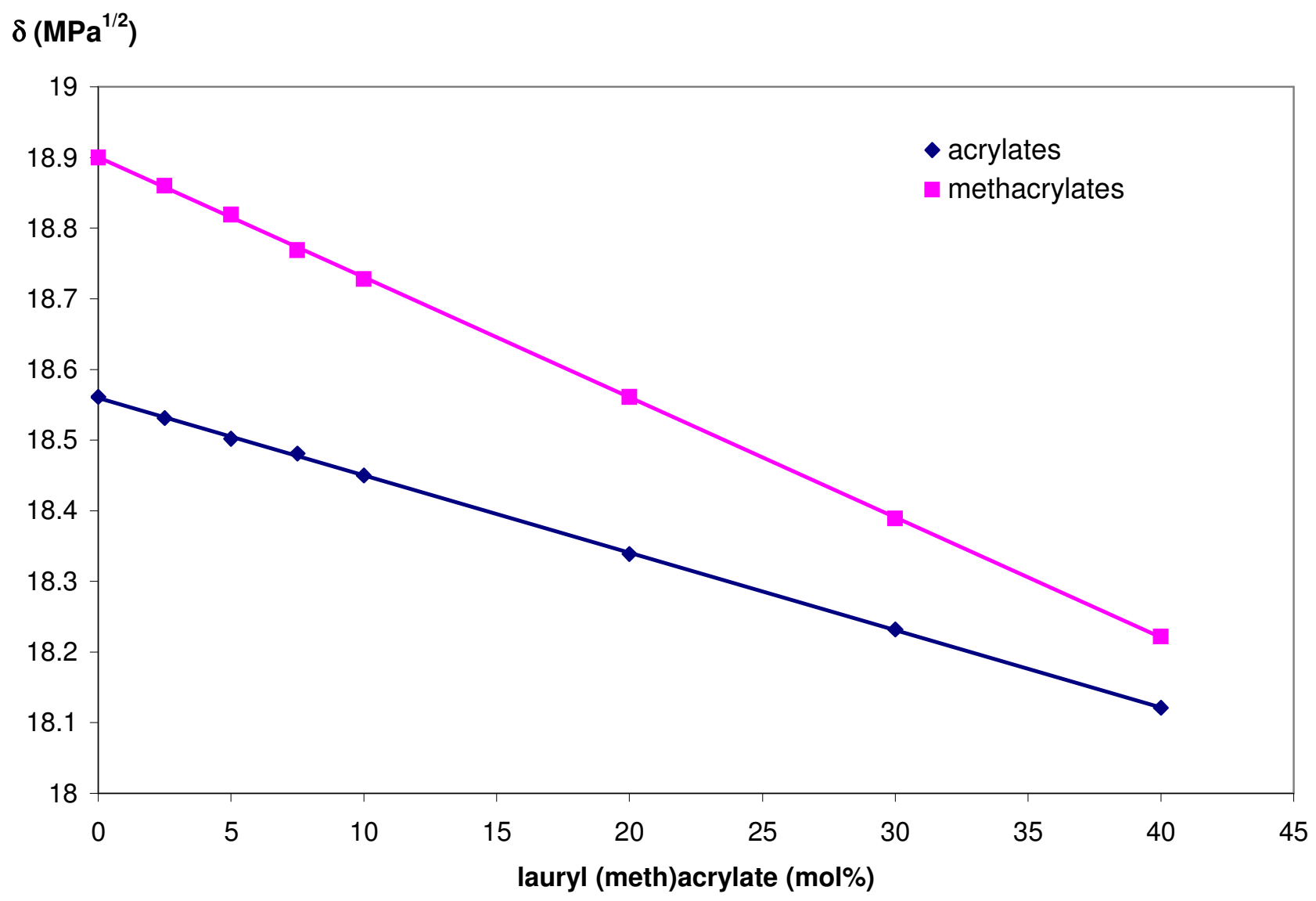

